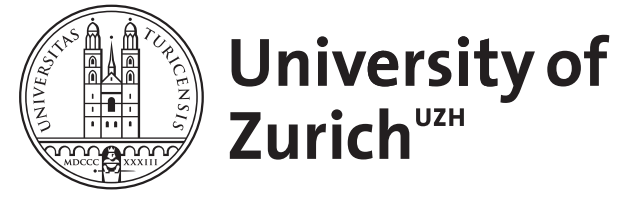

\title{
Präsenz - Memoria - Performativität. Überlegungen im Blick auf das Innsbrucker Fronleichnamsspiel
}

\author{
Kiening, Christian
}

Posted at the Zurich Open Repository and Archive, University of Zurich

ZORA URL: https://doi.org/10.5167/uzh-123763

Book Section

Published Version

Originally published at:

Kiening, Christian (2007). Präsenz - Memoria - Performativität. Überlegungen im Blick auf das Innsbrucker Fronleichnamsspiel. In: Kasten, Ingrid; Fischer-Lichte, Erika. Transformationen des Religiösen. Performativität und Textualität im geistlichen Spiel. Berlin: De Gruyter, 139-168. 


\title{
CHRISTIAN KIENING
}

\section{Präsenz - Memoria - Performativität \\ Überlegungen im Blick auf das Innsbrucker Fronleichnamsspiel}

\begin{abstract}
This article focuses on the alterity of the medieval religious play by historicizing three categories prominent in contemporary cultural studies: presence, memory and performativity. It argues for an understanding of the performative dimension of religious plays that takes the manuscripts not as poor records deprived of the multisensorial dynamics of actual representations but as rich texts oscillating between the production of presence and the enfolding of signification. The first German Corpus Christi play of 1391 seems a particularly apt example by which to demonstrate the intertwining of material and hermeneutical, symbolizing and de-symbolizing practices characteristic for the religious culture of the later Middle Ages.
\end{abstract}

Im Zuge der mediävistischen Historisierung des Textbegriffs sind traditionelle hermeneutische Kategorien wie Intentionalität, Abgeschlossenheit und Autonomie in ihrer analytischen Brauchbarkeit und Angemessenheit fragwürdig geworden. Zugleich sind neue Kategorien ins Zentrum getreten, die dem spezifischen Charakter mittelalterlicher Überlieferung näher zu kommen suchen und überdies Anschlüsse an Diskussionen der neueren Kultur- und Sozialwissenschaften herstellen. ${ }^{1}$ Dazu zählen unter anderem Präsenz, Memoria und Performativität. Beobachtet wurden Formen der Kommunikation, bestimmt durch Materialität, Körperlichkeit und Anwesenheit, Dimensionen von Schrift, geprägt durch Sinnlichkeit, Anschaulichkeit und Erscheinungshaftigkeit, Charakteristika epischer Welten, ausgezeichnet durch Glanz, Aura und Gegenwärtigkeit. Beobachtet wurden Formierungen textueller Gemeinschaften durch Bezugnahme auf eine Vergangenheit, die in die Gegenwart hineinwirkt, und

1 Vgl. zuletzt: ChrISTIAN KIENING: Zwischen Körper und Schrift. Texte vor dem Zeitalter der Literatur, Frankfurt a. M. 2003 (Fischer Tb. 15951); Retextualisierung in der mittelalterlichen Literatur. Hrsg. von JOACHIM BumKe/Ursula Peters, Berlin 2005 (ZfdPh 124. Sonderheft); ,Textus ${ }^{*}$ im Mittelalter. Komponenten und Situationen des Wortgebrauchs im schriftsemantischen Feld. Hrsg. von LUdOLF KUCHENBUCH/UTA KLEINE, Göttingen 2006 (Veröffentlichungen des Max-Planck-Instituts für Geschichte 216); Im Wortfeld des Textes. Worthistorische Beiträge zu den Bezeichnungen von Rede und Schrift im Mittelalter. Hrsg. von GERD DICKE/ MANFred EIKelmann/Burkhard Hasebrink, Berlin, New York 2006 (TMP 10). 
durch Wiederholung und Wiedergebrauch von Stoffen und Texten, die sich zwischen Situationsbezug und Situationsabstraktheit bewegen. Beobachtet wurden schließlich auch Dynamiken einer Kultur, die die Fülle des Sinns zwar in einem transzendenten Horizont verankert, gleichzeitig aber die Herstellung von Sinn an textuelle und visuelle, stimmliche und klangliche, mimische und musikalische Vollzüge und Partizipationen knüpft.

Bringt man diese hier nur knapp angedeuteten Aspekte auf Begriffe wie Präsenz, Memoria und Performativität, ist es nötig, diesen ihrerseits historische Trennschärfe zu verleihen: zum Beispiel im Hinblick auf aktuelle Theorien der Präsenz, Modelle von Gedächtnis und Erinnerung oder Ästhetiken des Performativen. ${ }^{2}$ Das könnte heißen: Präsenz nicht sosehr als Gegenbegriff zu Repräsentation zu verstehen, sondern im Spannungsfeld von Transzendenz und Immanenz zu verorten; ${ }^{3}$ Memoria nicht sosehr im Rahmen von prekärer Identitätsbildung und multimedialer Archivierung zu sehen, sondern als Basis historisch-überhistorischer Zeitenräume, die Vergangenes im Gegenwärtigen anwesend machen und auf dieses übertragen; ${ }^{4}$ Performativität nicht sosehr als Ausprägung einer mit statischen Modellen von Zeichen und Sprache, Kunst, Werk und Aufführung brechenden Ästhetik zu nehmen, sondern als Grundelement einer auf Vollzug, Prozessualität und Gemeinschaftlichkeit ruhenden kommunikativen Praxis. ${ }^{5}$ Die drei Begriffe wären also so zu fassen, dass sie

2 Vgl. ALEIDA ASSMANN: Erinnerungsräume. Formen und Wandlungen des kulturellen Gedächtnisses, München 1999; MARTIN SEEL: Ästhetik des Erscheinens, München 2000; DIETER MERSCH: Ereignis und Aura. Untersuchungen zu einer Ästhetik des Performativen, Frankfurt a. M. 2002 (edition suhrkamp 2210); ERIKA FISCHER-LICHTE: Ästhetik des Performativen, Frankfurt a. M. 2004 (edition suhrkamp 2373); HANS ULRICH GUMBRECHT: Diesseits der Hermeneutik. Die Produktion von Präsenz, Frankfurt a. M. 2004 (edition suhrkamp 2364).

3 Vgl. Christian KIENING: Ästhetik des Liebestods. Am Beispiel von Tristan und Herzmaere. In: din vil süezer sanc. Ästhetik im Mittelalter. Hrsg. von MAnUel Braun/Christopher YOUNG (im Druck). Zur höfischen Präsenzkultur CHRISTINA LECHTERMANN: Berührt werden. Narrative Strategien der Präsenz in der höfischen Literatur um 1200, Berlin 2005 (Philologische Studien und Quellen 191).

4 Vgl. Christian Kiening: Zeitenraum und mise en abyme. Zum ,Kern` der Melusinegeschichte. In: DVjs 79 (2005), S. 3-28. Grundlegend: Memoria. Der geschichtliche Zeugniswert des liturgischen Gedenkens im Mittelalter. Hrsg. von KARL SCHMID/JOACHIM WOLLASCH, München 1984 (Münstersche Mittelalter-Schriften 48); MARY J. CARRUTHERS: The Book of Memory. A Study of Memory in Medieval Culture, Cambridge 1990; Memoria als Kultur. Hrsg. von OTto GERHARD OEXLE, Göttingen 1995 (Veröffentlichungen des Max-Planck-Instituts für Geschichte 121); HORST WENZEL: Hören und Sehen, Schrift und Bild. Kultur und Gedächtnis im Mittelalter, München 1995.

5 Noch zu wenig trennscharf scheinen mir die Kategorien bei HANS RUdOLF Velten: Performativität. In: Germanistik als Kulturwissenschaft. Eine Einführung in neue Theoriekonzepte. Hrsg. von Claudia Benthien/Hans Rudolf Velten, Reinbek bei Hamburg 2002, S. 217 242, und bei der Arbeitsgruppe Wahrnehmung: Wahrnehmung und Performativität. In: Paragrana $13 / 1$ (2004), S. 15-80. 
sowohl die räumlich-materielle wie die zeitlich-soziale wie die semiotisch-prozessuale Dimension mittelalterlicher Textualität beschreibbar machen.

Das ist wichtig nicht zuletzt für ein Textcorpus, das in besonderer Weise die Historisierung der Beschreibungskategorien herausfordert. Geistliche Spiele haben - trotz einer reichen Forschung zu Einzeltexten, Abhängigkeiten und Traditionen - in dem Maße, in dem die methodologischen Implikationen der historischen Perspektive und des Konzepts von Theatralität in den Blick traten, auch irritiert. ${ }^{6}$ Geprägt durch stete Arbeit an autoritativen Prätexten und älteren Versionen ist ihr textueller und medialer Status schillernd. ${ }^{7}$ In der Überlieferung stehen verschiedene Formate, Anlagen und Funktionen nebeneinander, konkret: Dirigier- und Soufflierrollen, Exzerpt- und Entwurfstexte, Einzelfiguren- und Gesamtregiebücher neben Lese-, Erinnerungs- und Meditationshandschriften. ${ }^{8}$ In den Texten und ihren Kontexten treffen Biblisches, Theologisches und Liturgisches, Legendarisches und Erbauliches, Kirchliches und Außer-Kirchliches, Bildliches und Klangliches zusammen. ${ }^{9}$ Selbst die Grenzen zwischen Geistlichem und Weltlichem, Kirchenfestlich-Erhabenem und Fastnächtlich-Karnevaleskem sind gelegentlich fließend. ${ }^{10}$ Divergente,

6 Vgl. Hans UlRich GumBrecht: Für eine Erfindung des mittelalterlichen Theaters aus der Perspektive der frühen Neuzeit. In: Festschrift für Walter Haug und Burghart Wachinger. Hrsg. von JOHANNES JANOTA. Bd. 2, Tübingen 1992, S. 827-848; einen Überblick vermittelt HANSJÜRGEN LINKE: Drama und Theater als Feld interdisziplinärer Forschung. In: Euphorion 79 (1985), S. 43-65; DERS.: Drama und Theater. In: Die deutsche Literatur im späten Mittelalter, 1250-1370. Zweiter Teil: Reimpaargedichte, Drama, Prosa. Hrsg. von INGEBORG GLIER, München 1987 (Geschichte der deutschen Literatur III/2), S. 153-260.

$7 \mathrm{Zu}$ den textuellen Verbindungen am Beispiel der im Folgenden im Zentrum stehenden Spiele RUDOLF HÖPFNER: Untersuchungen zu dem Innsbrucker, Berliner und Wiener Osterspiel, Breslau 1913 (Germanistische Abhandlungen 45); BARBARA THORAN: Studien zu den österlichen Spielen des deutschen Mittelalters (Ein Beitrag zur Klärung ihrer Abhängigkeit voneinander), Göppingen ${ }^{2} 1976$ (GAG 199).

8 Rolf Bergmann: Aufführungstext und Lesetext: In: The Theatre in the Middle Ages. Hrsg. von HERMAN BRAET u.a., Leuven 1985, S. 314-351; DERS.: Katalog der deutschsprachigen geistlichen Spiele und Marienklagen des Mittelalters, München 1986 (Veröffentlichungen der Kommission für deutsche Literatur des Mittelalters der Bayerischen Akademie der Wissenschaften); HANSJÜRGEN LINKE: Versuch über deutsche Handschriften mittelalterlicher Spiele. In: Deutsche Handschriften 1100-1400. Oxforder Kolloquium 1985. Hrsg. von VOLKER HONEMANn/Nigel. F. PALMER, Tübingen 1988, S. 527-589; RolF BERGMANN: Geistliche Spiele des Mittelalters - Katalogerfassung und Neufunde. In: Osterspiele. Texte und Musik. Hrsg. von MAX SILLER, Innsbruck 1994 (Schlern-Schriften 293), S. 13-32.

9 Vgl. NiKol.AUS HeNKEL: Mediale Wirkungsstrategien des mittelalterlichen „Dramas“. Ein Beitrag zur Konstruktion literarischer Intermedialität. In: Medien der Kommunikation im Mittelalter. Hrsg. von KARL-HEINZ SPIESS, Stuttgart 2003, S. 237-263.

10 Vgl. HANSJÜRgEN LINKE: Unstimmige Opposition. „Geistlich“ und „weltlich“ als Ordnungskategorien der mittelalterlichen Dramatik. In: Leuvense Bijdragen 90 (2001), S. 75-126; UTE VON BLOH: Vor der Hölle. Fastnachtspiel (Keller 56) / Osterspiel / Emmausspiel. In: Ritual und Inszenierung. Geistliches und weltliches Drama des Mittelalters und der frühen Neuzeit. Hrsg. von HANS-JOACHIM ZiEgeler, Tübingen 2004, S. 233-246. 
teilweise konkurrierende Sinndimensionen gehen einher mit einer Zwischenstellung der Texte zwischen Kultisch-Rituellem, in dem sie nicht (mehr) aufgehen, und Spielerisch-Theatralischem, das (noch) keine Selbstständigkeit besitzt. ${ }^{11}$ Zwar gibt es Signale, die auf die Differenz zwischen Handlungs- und Gegenwartswirklichkeit hinweisen, und Freiräume, in denen die Bindung an die heilsgeschichtlichen Grundlagen zurücktritt. Doch bleibt das Moment partizipatorischer Vergegenwärtigung ebenso zentral wie dasjenige einer Vermittlung theologischer Gehalte und frömmigkeitspraktischer Normen - auch wenn diese, zum Beispiel indem sie sich "mythischer" Absolutismen bedienen, kerygmatischen und dogmatischen Eindeutigkeiten entgegenlaufen können. ${ }^{12}$ Angesichts solcher Gegebenheiten erweisen sich Vorstellungen neuzeitlicher oder moderner Theatralität als anachronistisch. Wo die Wirklichkeit des Spiels als heilsgeladene und transzendenzdurchlässige begriffen ist, wird man weniger nach den Nuancen der Inszenierung zu fragen haben als nach den Konfigurationen, die eine von Kult und Ritual genährte und doch nicht völlig von diesen bestimmte Geltung ermöglichen. Den das Heilsgeschehen vergegenwärtigenden und zugleich deutenden Institutionen Geltung zu verschaffen ist schon das Anliegen der Liturgie. Sie benutzt Zeitliches und Räumliches, Architekturelemente und Objekte, Körper und Gesten, Bewegungen und Prozessionen, Worte und Gesänge, die aufgrund ihrer strengen Codifizierung und ihres rituellen Charakters sowohl Verbindlichkeit wie Wiederholbarkeit garan-

11 JAN-DIRK MÜLLER: Kulturwissenschaft historisch. Zum Verhältnis von Ritual und Theater im späten Mittelalter. In: Lesbarkeit der Kultur. Literaturwissenschaften zwischen Kulturtechnik und Ethnographie. Hrsg. von Gerhard Neumann/Sigrid Weigel, München 2000, S. 53-77; INGRID KASTEN: Ritual und Emotionalität. Zum Geistlichen Spiel des Mittelalters. In: Literarische Leben. Rollenentwürfe in der Literatur des Hoch- und Spätmittelalters. Hrsg. von Matthias Meyer/Hans-JOChen SChiEwer, Tübingen 2002, S. 335-359; Ritual und Inszenierung. Geistliches und weltliches Drama des Mittelalters. Hrsg. von HANS-JOACHIM ZIEGELER, Tübingen 2004; Das Theater des Mittelalters und der frühen Neuzeit als Ort und Medium sozialer und symbolischer Kommunikation. Hrsg. von CHRISTEL MEIER/HEINZ MEYER/ Claudia Spanily, Münster 2004; Christoph Petersen: Ritual und Theater. Meßallegorese, Osterfeier und Osterspiel im Mittelalter, Tübingen 2004 (Münchener Texte und Untersuchungen zur deutschen Literatur des Mittelalters 125).

12 Vgl. Rainer WARning: Funktion und Struktur. Die Ambivalenzen des geistlichen Spiels, München 1974 (Theorie und Geschichte der Literatur und der Schönen Künste 35); Anknüpfungen bei JAN-DIRK MÜLLER: Mimesis und Ritual. Zum geistlichen Spiel des Mittelalters. In: Mimesis und Simulation. Hrsg. von Andreas Kablitz/Gerhard NeumanN, Freiburg i. Br. 1998, S. 541-571; BRUNO QUAST: Vom Kult zur Kunst. Öffnungen des rituellen Textes in Mittelalter und früher Neuzeit, Tübingen 2005 (Bibliotheca germanica 48); kritischer WALTER HAUG: Rainer Warning, Friedrich Ohly und die Wiederkehr des Bösen im geistlichen Schauspiel des Mittelalters: In: DERS.: Die Wahrheit der Fiktion. Studien zur weltlichen und geistlichen Literatur des Mittelalters und der frühen Neuzeit, Tübingen 2003, S. 650-663. Zu den mythischen Absolutismen vgl. CHRISTIAN KIENING: Arbeit am Absolutismus des Mythos. Mittelalterliche Supplemente zur biblischen Heilsgeschichte. In: Präsenz des Mythos im Mittelalter. Hrsg. von Udo Friedrich/Bruno QUAST, Berlin, New York 2004 (TMP 2), S. 35-57. 
tieren. ${ }^{13}$ Die Verknüpfung sinnstiftender, sinngestaltender, sinnvergewissernder und sinnerneuernder Aspekte der „Kommunikation des Evangeliums“ ${ }^{\text {“14 }}$ verknüpft zugleich anthropologische und theologische Dimensionen und schlägt dadurch den Bogen zwischen Abstraktheit und Konkretheit, Transzendenz und Immanenz, Vergangenheit und Gegenwart. Geistliche Spiele nehmen diese Dimensionen (in unterschiedlicher Weise) in sich auf, indem sie sich ebenfalls der vergegenwärtigenden Erinnerung eines historisch-überhistorischen Heilsgeschehens widmen. Sie erweitern sie aber auch in räumlicher und zeitlicher Hinsicht, indem sie über die klerikal-sakralen Räume und die liturgisch-festlichen Zeiten hinausgreifen. Das Problem der theologischen Geltung, das damit einhergeht, wird aufgefangen durch das Potenzial der sozialen Geltung, welche dargestellte Heilswirklichkeit und darstellende Gegenwartswirklichkeit verbindet. Zugleich verschiebt sich das Verhältnis nicht-mimetischer und mimetischer Elemente. Spielen die mimetischen in der Liturgie, verglichen mit der Dominanz symbolisch codierter Analogiehandlungen, nur in Szenen wie der Visitatio eine Rolle, treten sie im Spiel in den Vordergrund. Es kommt zu einer Überlagerung verschiedener Formen der Evidenz, wie sie den zum einen weiterhin symbolischen, zum andern vermehrt indexikalischen Zeichen zu eigen ist.

Das verbindet die Spiele mit anderen Dialogisierungen und Dramatisierungen von Heilsgeschehen und Heilswissen, die sich in der (lauten oder leisen) Lektüre oder der (meditativen oder reflexiven) Betrachtung vollziehen. ${ }^{15}$ Jeweils

13 Zum dramatischen Charakter liturgischen Geschehens OSBORNE B. HARDISON, JR.: Christian Rite and Christian Drama in the Middle Ages. Essays in the Origin and Early History of Modern Drama, Baltimore 1965; JAN-DIRK MÜLLER: Realpräsenz und Repräsentation. Theatrale Frömmigkeit und Geistliches Spiel. In: Ritual und Inszenierung. Geistliches und weltliches Drama des Mittelalters und der frühen Neuzeit. Hrsg. von HANS-JOACHIM ZIEGELER, Tübingen 2004, S. 113-133.

14 KARL-HeInRICH BIERITZ: Liturgik, Berlin, New York 2004, S. 9.

15 Vgl. James H. MARRow: Passion lconography in Northern European Art of the Late Middle Ages and Early Renaissance. A Study of the Transformation of Sacred Metaphor into Descriptive, Kontrijk 1979; FrITZ O. SCHUPPISSER: Schauen mit den Augen des Herzens. Zur Methodik der spätmittelalterlichen Passionsmeditation, besonders in der Devotio moderna und bei den Augustinern. In: Die Passion Christi in Literatur und Kunst des Spätmittelalters. Hrsg. von Walter Haug/Burghart WaChinger, Tübingen 1993 (Fortuna vitrea 12), S. 169-210; SARAH BECKWITH: Christ's Body. Identity, Culture and Society in Late Medieval Writings, London, New York 1993; HENK VAN OS u.a.: The Art of Devotion in the Middle Ages in Europe 1300-1500. Ausstellungskatalog Rijksmuseum Amsterdam, London 1994; JEFFREY F. HAMBURGER: Nuns as Artists. The Visual Culture of a Medieval Convent. Berkeley, Los Angeles, London 1997; DERS.: The Visual and the Visionary. Art and Female Spirituality in Late Medieval Germany, New York 1998; THOMAS LENTES: Andacht und Gebärde. Das religiöse Ausdrucksverhalten zwischen 1300 und 1600. In: Kulturelle Reformation. Sinnformationen im Umbruch (1400-1600). Hrsg. von BernhaRD JUSSEN/CRAIG KOSLOFSKY, Göttingen 1998 (Veröffentlichungen des Max-Planck-Institutes für Geschichte 145), S. 29-67; DERS.: Auf der Suche nach dem Ort des Gedächtnisses. In: Imagination und Wirklichkeit. Zum Verhältnis von mentalen und realen Bildern in der frühen Neuzeit. Hrsg. von Klaus KRÜGER/AlesSANDro 
bedeutet Memoria hier imaginative Ausgestaltung des kanonischen Materials und prospektive Verlängerung des Blicks in die Zukunft hinein, in der sich die individuelle wie kollektive Heilsgeschichte erfüllt. Jeweils geht es um verinnerlichende Verkörperungen und verkörperlichende Verinnerlichungen mittels Gestalthaftem, Szenischem, Anschaulichem, das Heil repräsentierbar und übertragbar macht. So wie figura sowohl Zeichenhaftes wie Wirkliches benennen kann, ${ }^{16}$ so umgreift auch repraesentatio Modalitäten sowohl des Darstellens wie des Gegenwärtigmachens. ${ }^{17}$ Zumindest grundsätzlich herrscht also auch in den Spielen, wie in religiösen Bildern und Texten, der Anspruch, im Vollzug der Lektüre oder der Wahrnehmung Heil zum Erscheinen zu bringen und in der Reflexion eine Steigerung von Nähe und Unmittelbarkeit zu ermöglichen. Andererseits unterscheiden sich die Spiele aber von den Bildern und Texten genau dadurch, dass sie Modelle eines performativen Handelns bieten, in denen die figürliche Verkörperung Als-ob-Status hat, und dass sie Modelle eines Handelns bieten, an dem eine größere Gemeinschaft von Agierenden und Rezipierenden beteiligt ist. Benutzt werden die (ihrerseits noch keineswegs ausdifferenzierten) Prinzipien der anderen Medien: die Sukzessivität der textuellen narratio und die Simultanität der visuellen institutio, ${ }^{18}$ um einem in

NovA, Mainz 2000, S. 1-35; DERS.: Inneres Auge, äußerer Blick und heilige Schau. Ein Diskussionsbeitrag zur visuellen Praxis in Frömmigkeit und Moraldidaxe des späten Mittelalters. In: Frömmigkeit im Mittelalter. Politisch-soziale Kontexte, visuelle Praxis und körperliche Ausdrucksformen. Hrsg. von KLAUS SCHREINER, München 2002, S. 179-219; Spiegel der Seligkeit. Privates Bild und Frömmigkeit im Spätmittelalter. Hrsg, von G. UlRICH GrossmanN. Ausstellungskonzept und Katalog FranK MATTHIAS KAMMEL, Nürnberg 2000 (Ausstellungskataloge des Germanischen Nationalmuseums).

16 Vgl. Georges Didi-Huberman: Fra Angelico. Unähnlichkeit und Figuration, München 1995, S. 30, 44 f. u. ö.; Christian KIENING: Das andere Selbst. Figuren des Todes an der Schwelle zur Neuzeit, München 2003; speziell zum geistlichen Spiel WOLFGANG FrIedRICH MichaEL: Die Bedeutung des Wortes Figur im geistlichen Drama Deutschlands. In: Germanic Review 21 (1946), S. 3-8.

17 Zum repraesentatio-Begriff Hasso HOFFMANN: Repräsentation. Studien zur Wort- und Begriffsgeschichte von der Antike bis ins 19. Jahrhundert, Berlin 1974 (Schriften zur Verfassungsgeschichte 22); Höfische Repräsentation. Das Zeremoniell und die Zeichen. Hrsg. von Hedda Ragotzky/Horst Wenzel, Tübingen 1990; Ursula Schulze: Formen der Repraesentatio im Geistlichen Spiel. In: Mittelalter und frühe Neuzeit. Übergänge, Umbrüche und Neuansätze. Hrsg. von WALter Haug, Tübingen 1999 (Fortuna vitrea 16), S. 312-356. Im deutschsprachigen Raum begegnet gegenüber dem häufigen ludus der Begriff repraesentatio nur einmal als Bezeichnung eines geistlichen Spiels; vgl. ERWIN WOLFF: Die Terminologie des mittelalterlichen Dramas in bedeutungsgeschichtlicher Sicht. In: Anglia 78 (1960), S. 127; Rolf Bergmann/Stefanie Stricker: Zur Terminologie und Wortgeschichte des Geistlichen Spiels. In: Mittelalterliches Schauspiel (Festschrift Hansjürgen Linke), Amsterdam 1994 (Amsterdamer Beiträge zur älteren Germanistik 38/39), S. 49-77; MATTHIAS SCHULZ: Die Eigenbezeichnungen des mittelalterlichen deutschsprachigen geistlichen Spiels, Heidelberg 1998 (Germanistische Bibliothek 2).

18 Vgl. HANNS Peter NeUHEUSER: Zugänge zur Sakralkunst. Narratio und institutio des mittelalterlichen Christgeburtsbildes, Köln, Weimar, Wien 2001. 
Text und Bild autoritativ fixierten religiösen Gehalt kommemorative Präsenz und sinnliche Evidenz zu verschaffen. Diese Präsenz und diese Evidenz liegen nicht erst in der mimetischen Umsetzung. Sie wohnen bereits der nichtmimetischen Schrift inne, deren Möglichkeiten diejenigen, die die Spiele aufzeichnen, ausloten. Von diesen Möglichkeiten zeugen auch die zahlreichen Regiebemerkungen und Rollenkennzeichnungen, Notenaufzeichnungen und Aufführungsnotizen. Sie machen zwar nicht die Umsetzung von Spieltext in Spielhandlung rekonstruierbar, lassen aber die Bedingungen erkennen, unter denen Texte wie diese funktionieren. ${ }^{19}$

Texte wie diese heißt: Spieltexte ebenso wie Spielbeschreibungen. Auch die letzteren sind ja nicht einfach Dokumente. Sie sind Monumente und Instrumente. Sie setzen spezifische Akzente - etwa im Sinne einer Kritik an populär-profanen Praktiken oder einer Kontrastierung von kontingentem Spiel und providentiellem Plan. Ich nenne nur zwei Beispiele. Zum einen die vielzitierten Berichte über das 1321 in Eisenach gespielte Zehnjungfrauenspiel und die daraus erwachsene Erschütterung Friedrichs des Freidigen. ${ }^{20}$ Sie sind Exempel nicht nur für die Wirksamkeit des geistlichen Spiels, sondern auch für den Zweifel an der göttlichen Ordnung und das unrühmliche Ende eines Geschlechts (der Staufer). Zum andern die Geschichte des im Umfeld einer Aufführung wiedererweckten Jungen, überliefert in einer zwischen 1211 und 1219 entstandenen Sammlung von post mortem geschehenen Mirakeln, bezogen auf den Heiligen des frühen 8. Jahrhunderts John von Beverley (Ioannes Beverlacensis). Sie demonstriert die Macht der göttlichen Gnade und ihre Übertragung auf das mit Johannes verknüpfte Gotteshaus: ${ }^{21}$ Bei einer im Sommer auf dem Friedhof an der Nordseite der Kirche gespielten reprcesentatio Dominica Resurrectionis seien einige Jungen an den Bögen der Kirche hochgeklettert,

19 BERND NeumanN: Geistliches Schauspiel im Zeugnis der Zeit. Zur Aufführung mittelalterlicher religiöser Dramen im deutschen Sprachgebiet. 2 Bde., München 1987 (Münchener Texte und Untersuchungen zur deutschen Literatur des Mittelalters 84/85). Zu den städtischen Kontexten der großen Spiele KLAUS WOLF: Kommentar zur ,Frankfurter Dirigierrolle' und zum ,Frankfurter Passionsspiel', Tübingen 2002 (Die Hessische Passionsspielgruppe. Edition im Paralleldruck. Ergänzungsbd. 1); DOROTHEA FrEISE: Geistliche Spiele in der Stadt des ausgehenden Mittelalters. Frankfurt - Friedberg - Alsfeld, Göttingen 2002 (Veröffentlichungen des Max-Planck-Instituts für Geschichte 178); Rez. durch JOHANNES JANOTA. In: ZfdA 134 (2005), S. 244-261.

20 Neumann (Anm. 19), Bd. 1, S. 306-308, Nr. 1481-83; zu den Texten: HansuÜrgen LinKe: ,Thüringische Zehnjungfrauenspiele'. In: Die deutsche Literatur des Mittelalters. Verfasserlexikon. Zweite, völlig neu bearbeitete Aufl., Bd. 9 (1995), Sp. 915-918; RENATE AMSTUTZ: Ludus de decem virginibus. Recovery of the Sung Liturgical Core of the Thuringian Zehnjungfrauenspiel, Toronto 2002 (Studies and Texts 140).

21 Text: Acta Santorum: Mai Il, Antwerpen 1680, Sp. 189 B/C; dazu SuSAN E. Wilson: The Cult of St John of Beverly, Diss. Southampton 2001; DIES.: Resurrection: Representation v. Reality In a Miracle of St John of Beverly. In: Medieval Forum (unter: http://www.sfsu.edu/ $\sim$ medieval/Volume $\% 201 /$ Wilson.html). 
um durch die Turm- oder die Glasfenster einen besseren Blick auf das von einer großen Menge umgebene Spektakel zu haben. Von Wächtern verfolgt, sei einer der Jungen bis zu einem großen Kreuz, über dem Altar des Hl. Martin angebracht, gelangt und aufgrund eines sich lösenden Quadratsteins abgestürzt. Gott habe, um keinen Schaden über die Kirche und ihren Stifter kommen zu lassen, dem scheinbar Toten Leben und Unversehrtheit wiedergeschenkt - eine Parallele zu der im Spiel vergegenwärtigten resurrectio Christi. Sie wird unterstrichen dadurch, dass der Autor Fall und Auferstehung mit dem Verhältnis von menschlicher und göttlicher Natur in Verbindung bringt: Unde cujus Passionis secundum humanitatem signum fuit ruina, ejus etiam Resurrectionis secundum Divinitatem exstitit erectio miraculosa (,so wie daher der Fall ein Zeichen seiner Passion in Bezug auf die menschliche Natur war, so war die wunderbare Erhebung eines der Auferstehung in Bezug auf die göttliche").

Das Spiel, aufgeführt traditionsgemäß, wie es heißt, sowohl mit Worten wie mit Gesten in Kostümen oder Masken (larvatorum (ut assolet) \& verbis \& actu), behandelt zwar ein zentrales geistliches Thema. Es erfolgt aber ohne feste liturgische Anbindung und mit keiner klar erbaulichen Wirkung: manche derer, die nicht genug sehen konnten, hätten sich lieber in die Kirche begeben, um zu beten, die Malereien zu betrachten oder Ruhe zu suchen (ut vel orarent, vel picturas inspicient, vel per aliquod genus recreationis \& solatii pro hoc die tcedium evitarent). Das Spiel steht also in medialer Konkurrenz zu anderen Formen der Heilsvergewisserung und dient im Kontext des Mirakels vor allem dazu, die Differenz zu markieren zu dem, was das eigentliche Ereignis ausmacht: die Auferstehung, die nicht nur spielerische Nachahmung des elementar christlichen Geschehens ist, sondern dessen mirakulöse Wiederholung. Auch hier erhält man also einen Einblick weniger in die performativen Realitäten mittelalterlicher Spiele als in die textuellen Praktiken heilsbezogener Sinnstiftung. Im Aufgreifen verschiedener Medien des Heils (Kirchenraum, Bilder, Spiel, Text) wird ein Moment der klerikalen Kritik an der Verselbstständigung mimischer Vergegenwärtigung so eingesetzt, dass sich das Heilsdrama auf den Text des Mirakels übertragen kann. ${ }^{22}$

22 Zwei Dekrete Papst Innozenz' III. hatten 1207 und 1210, kurz vor dem Entstehen der Mirakelsammlung, die Gewohnheit, ludi theatrales und spectacula in monstra larvarum aufzuführen, untersagt; NEUMANN (Anm. 19), Bd. 2, S. 869; generell zur kirchlichen Position WERNER WeISMANN: Kirche und Schauspiele. Die Schauspiele im Urteil der lateinischen Kirchenväter unter besonderer Berücksichtigung von Augustin, Würzburg 1972 (Cassiciacum 27); CHRISTINE SCHNUSENBERG: Das Verhältnis von Kirche und Theater. Dargestellt an ausgewählten Schriften der Kirchenväter und liturgischen Texten bis auf Amalarius von Metz (a.d. 775852), Bern u.a. 1981 (EHS XXIIl, 141); TheOfRIED BAuMEISTER: Das Theater in der Sicht der Alten Kirche. In: Theaterwesen und dramatische Literatur. Beiträge zur Geschichte des Theaters. Hrsg. von GüNTER HolTus, Tübingen 1987 (Mainzer Forschungen zu Drama und Theater 1), S. 109-124. 
Die Kategorie der Aufführung muss zum Problem werden, wenn man die Überlieferung primär als unzureichende Aufzeichnung umfassender, aber verlorener Sinnzusammenhänge begreift, die ,der heutige Interpret [...], soweit es nur irgend möglich ist, aus ihr herauszulesen versucht"“ ${ }^{23}$ Sie kann zur Chance werden, wenn die historische Rekonstruktion den Blick auf die Faktizität und Materialität der Überlieferung nicht preisgibt. Dann eröffnet sich in dem, was sich theatergeschichtlich verschlie $\beta t$, schrift- und textgeschichtlich ein Feld, auf dem Bedingungen der Möglichkeit von textueller Performativität verfolgt werden können. Eine solche textuelle Performativität wäre nicht identisch mit der rein sprachlich-semiotischen Dimension von Performativa im Sinne der älteren Sprechakttheorie. Sie wäre aber auch nicht identisch mit der konkreten (mimischen oder korporalisierenden) Performanz der jüngeren Kultur- und Theaterwissenschaften. ${ }^{24}$ Sie beträfe eher die prinzipielle Ereignishaftigkeit eines Vollzugs, der dem Text eingeschrieben ist: in seinen sprachlichen, dialogischen und szenischen Dynamiken, seinen präsentativen, evokativen und signifikativen Dimensionen, seinen syntagmatischen und paradigmatischen Spannungen. ${ }^{25}$ Die Aufzeichnung wäre eine ,Partitur ${ }^{26}$ nicht in dem Sinne, dass sie in der Rezeption konkretisiert wird, sondern in dem Sinne, dass sie wie die Transzendenz ihres Sinnes auch die Transzendierung ihrer Medialität herauszustellen vermag. ${ }^{27}$ Das aber hieße, weniger von einer Dichotomie von

23 LinKE (Anm. 8), S. 527. Um die ,Aufführungswirklichkeit' geht es auch KLAUS WOLF: Für eine neue Form der Kommentierung geistlicher Spiele. Die Frankfurter Spiele als Beispiel der Rekonstruktion von Aufführungswirklichkeit. In: Ritual und Inszenierung. Geistliches und weltliches Drama des Mittelalters und der frühen Neuzeit. Hrsg. von HANS-JOACHIM ZIEGELER, Tübingen 2004, S. 273-312.

24 Zum Verhältnis zwischen beiden vgl. den Band: Performanz. Zwischen Sprachphilosophie und Kulturwissenschaften. Hrsg. von UWE WIRTH, Frankfurt a. M. 2002 (suhrkamp taschenbuch wissenschaft 1575); zur Abhängigkeit der Performanz von Schrift JAN-DIRK MÜLLER: Ritual, pararituelle Handlungen, Geistliches Spiel. Zum Verhältnis von Schrift und Performanz. In: Audiovisualität vor und nach Gutenberg. Zur Kulturgeschichte der medialen Umbrüche. Hrsg. von Horst Wenzel/Wilfried Seipel/Gotthart Wunberg, Wien 2001 (Schriften des Kunsthistorischen Museums 6), S. 63-71. Ein neues mediales Modell von Performativität wird sichtbar bei SYBILLE KRÄMER (Hg.): Performativität und Medialität. München 2004.

25 Vgl. PETER STROHSCHNEIDER: Aufführungssituation: Zur Kritik eines Zentralbegriffs kommunikationsanalytischer Minnesangforschung. In: Kultureller Wandel und die Germanistik in der Bundesrepublik. Vorträge des Augsburger Germanistentages 1991. Bd. 3: Methodenkonkurrenz in der germanistischen Praxis. Hrsg, von JOHANNES JANOTA, Tübingen 1993, S. 56-71.

26 Der Begriff wird am Beispiel der mittelalterlichen Liedüberlieferung erprobt von HEDWIG MeIER/Gerhard LAuer: Partitur und Spiel. Die Stimme der Schrift im ,Codex Buranus'. In: ,Aufführung' und 'Schrift' in Mittelalter und Früher Neuzeit. Hrsg. von JAN-DiRK MüLLER, Stuttgart, Weimar 1996 (Germanistische Symposien. Berichtsbd. 17), S. 31-47, sowie von MARTIN HUBER: Fingierte Performanz. Überlegungen zur Codifizierung spätmittelalterlicher Liedkunst, im gleichen Band S. 93-106.

27 Vgl. KRÄMER, Performativität (Anm. 24), Einleitung, S. 21: „Vielmehr erfasst ,Performativität' eine Dimension aller kulturellen Praktiken im Spannungsverhältnis zwischen einem Ereignis und seiner Wahrnehmung; und zwar soweit dieses Verhältnis so beschrieben werden kann, 
,Aufführungstexten ${ }^{`}$ und ,Lesetexten ${ }^{28}$ auszugehen denn von der Frage, welche Praktiken der Verinnerlichung wie der Veräußerlichung generell zu beobachten seien. Jede Zuweisung von Gebrauchsformen hängt ja bereits an den Modellen, in denen die Funktion der Texte und der Aufführungen gedacht wird.

\section{II}

Das zeigt sich exemplarisch an den Schwierigkeiten, eine so zentrale und relativ frühe Handschrift wie den 1391 im Thüringischen entstandenen, dann ins Augustiner-Chorherrenstift Neustift gelangten und heute in Innsbruck aufbewahrten Cod. 960 einzustufen. ${ }^{29}$ Der Codex vereint, von gleicher Hand geschrieben, einen ludus de assumptione beate Marie virginis, einen ludus de resurrectione domini und einen ludus de corpore Christi. Doch er ist weder eindeutig auf Inszenierung noch auf Lektüre bezogen:

dass das, was ein Akteur hervorbringt, von Betrachtern auf eine Weise rezipiert wird, welche die Symbolizität und Ausdruckseigenschaften dieses Vollzugs gerade überschreitet."

Zur Diskussion über Aufführungstext und Lesetext WERNER WILLIAMS-KRAPP: Überlieferung und Gattung. Zur Gattung ,Spiel ${ }^{*}$ im Mittelalter. Mit einer Edition von ,Sündenfall und Erlösung' aus der Berliner Handschrift mgq 496, Tübingen 1980 (Untersuchungen zur deutschen Literaturgeschichte 28); BERGMANN, Rez. Williams, in: AfdA 93 (1982), S. 164-166; DERS. (Anm. 8); LINKE (Anm. 8); CHRISTOPH GERHARDT: Zur Spieltradition von ,Sündenfall und Erlösung'. Mit textkritischen und kommentierenden Bemerkungen zum Text. In: Sancta Treveris. Beiträge zu Kirchenbau und Bildender Kunst im alten Erzbistum Trier. Festschrift für Franz J. Ronig zum 70. Geburtstag. Hrsg. von MiChael EMBACH u.a., Trier 1999, S. 173208; DERS.: Von der biblischen Kleinerzählung zum geistlichen Spiel. Zur Neubestimmung der Gattung von Von Luzifers und Adams Fall und zu seiner Stellung in der Spieltradition. In: Euphorion 93 (1999), S. 349-397. Zu Übergängen auch ElisABETH MEYER: Zur Überlieferungsfunktion des Heidelberger Passionsspiels: Von einer Spielvorlage zur erbaulichen Lektüre? In: Leuvense Bijdragen 90 (2001), S. 145-159.

29 Altteütsche Schauspiele. Hrsg, von FrANZ JOSEPH MONE, Quedlinburg und Leipzig 1841 (Bibliothek der gesammten deutschen National-Literatur 21): Innsbrucker Spiel von Mariae Himmelfahrt (abgekürzt IHM), Innsbrucker Osterspiel (abgekürzt IO), Innsbrucker Fronleichnamsspiel (abgekürzt IF). MONES Lesungen wurden im Folgenden gelegentlich korrigiert an: Die Neustifter-Innsbrucker Spielhandschrift von 1391 (Cod. 960 der Universitätsbibliothek Innsbruck). In Abbildung hrsg. von Eugen Thurnher/WALter NeuHauser, Göppingen 1975 (Litterae 40). Zur Handschrift HANS MOSER: Die Innsbrucker Spielhandschrift in der geistlichen Spieltradition Tirols. In: Tiroler Volksschauspiel. Beiträge zur Theatergeschichte des Alpenraumes. Hrsg. von EGON KÜHEBACHER, Bozen 1976 (Schriftenreihe des Südtiroler-Kulturinstituts 3), S. 178-189; BARBARA THORAN: Das Osterspiel der Innsbrucker Handschrift Cod. 960 - ein Neustifter Osterspiel, im gleichen Band S. 360-379; BergmanN, Katalog (Anm. 8), S. 160-163 (Nr. 67); BARBARA THORAN: Fragen zu Herkunft und Nachwirkung des Innsbrucker Thüringischen Osterspiels. In: Osterspiele. Texte und Musik. Hrsg. von MAX SILLER, Innsbruck 1994 (Schlern-Schriften 293), S. 187-202; Jens HausteIn/WINFRIED NEUMANN: Zur Lokalisierung der Innsbrucker (thüringischen) Spielhandschrift. In: Magister et amicus (Festschrift Kurt Gärtner). Hrsg. von VACLAV BOK/FRANK SHAW, Wien 2003, S. 385-394. 
Das schmale Hochformat $(28 \times 11 \mathrm{~cm})$, die durch Farbe und Schrift hervorgehobenen Regieanweisungen und die Wiedergabe der vollständigen Rollentexte (ohne Noten) sind zwar eindeutige Merkmale für ein Regiebuch, aber es fehlen jegliche Hinweise für eine Aufführung des Spiels auf der Grundlage dieses Regiebuchs. Von einer Aufführungshandschrift kann man also nur insofern sprechen, als ihr das Regiebuch einer früheren Aufführung zugrunde liegt und der Text die Grundlage für eine künftige Inszenierung des Spiels bilden konnte. Es handelt sich also um eine Spieltextarchivierung in Form eines Regiebuchs. Dafür spricht auch, daß dem Osterspiel das Innsbrucker Spiel von Mariae Himmelfahrt vorausgeht und dem Osterspiel das Innsbrucker Fronleichnamspiel folgt. ${ }^{30}$

So treffend JANOTA die Gegebenheiten beschreibt - man sollte den Begriff der Archivierung wohl nicht so verstehen, als sei mit ihm ein System von Diskursivität und Regularität, eine universale Ordnung und Verfügbarkeit des Wissens schon vorausgesetzt. ${ }^{31}$ Es gibt Anzeichen dafür, dass das Wissen der vormodernen Gesellschaft ein nicht sosehr zu möglicher späterer Nutzung zu archivierendes und zu sicherndes wäre als vielmehr eines, das, eine vorgängige Weltordnung reproduzierend, immer sowohl auf den Gebrauch wie das Gegenwärtige gerichtet ist. Auch die Spiele in einer Handschrift wie der Innsbrucker böten dann nicht die Stillstellung der Aufführungen, die ihrer Niederschrift vorangehen und nachfolgen, nicht das Sediment dessen, was sich ereignet hat und wieder ereignen kann. Sie böten etwas, was der Unterscheidung von Text und Aufführung ebenso vorausläge wie der von Nachvollziehen und Spielen. ${ }^{32}$ Sie wären selbst in ihrer materiellen Realisierung nicht zu trennen von der imaginativen Dimension, in der sie sich ,abspielen'.

Dies wiederum, so meine These, ließe sich gerade mit Hilfe der Kategorien der Präsenz, der Memoria und der Performativität erkennen, weil sie je eigene Aspekte der Alterität des geistlichen Spiels in den Blick zu nehmen erlauben: nämlich die Eigentümlichkeit einer Präsenz, die zwischen dem Unsichtbaren und dem Sichtbaren oszilliert; die Spezifik einer Memoria, die im Rückgriff auf die Vergangenheit zugleich den Ausgriff auf die Zukunft und die Verwandlung des Zeitlichen ins Überzeitliche perspektiviert; das Besondere einer Performativität, die sich als innere Dynamik heilsgeschehentlicher Entfaltung vollzieht. Und dies wiederum ließe sich vielleicht am deutlichsten an einer Form erkennen, die nicht wie im Falle des Osterspiels an die traditionellen

30 JOHANNES JANOTA: Orientierung durch volkssprachige Schriftlichkeit (1280/90-1380/90), Tübingen 2004 (Geschichte der deutschen Literatur von den Anfängen bis zum Beginn der Neuzeit 11I/1), S. 359.

31 Zum Archiv zuletzt ThOMAs DEgener: Speicher der kulturellen Erinnerung oder Motor des kulturellen Wandels? Überlegungen zum Stellenwert des Archivs im kulturwissenschaftlichen Diskurs. In: Sichtungen 3 (2000), S. 73-89; GISELA FEBEL: Michel Foucaults Begriff des Archivs und das Modell des historischen Romans. In: Internationale Zeitschrift für Philosophie H. 1 (2000), S. 63-81; WolfGang ERNST: Das Rumoren der Archive. Ordnung aus Unordnung, Berlin 2002; MORITZ BASSLER: Die kulturpoetische Funktion und das Archiv. Eine literaturwissenschaftliche Text-Kontext-Theorie, Tübingen 2005. 
Abläufe der Liturgie und nicht wie im Falle des Passionsspiels an die kanonischen Berichte der Evangelien anschließt, eine Form, die nicht den mimetischen Nachvollzug ins Zentrum stellt, sondern eigene Vollzüge und Steigerungseffekte kreiert: so im Falle der Fronleichnamsfestes und des Fronleichnamsspiels, als dessen erster deutschsprachiger Vertreter das dritte der Innsbrucker Spiele begegnet. ${ }^{33}$

Beide, Fest wie Spiel, stehen im Kontext einer Entwicklung, die im 11. und 12. Jahrhundert entscheidende Impulse bekommt und im 13. Institutionalisierungen zeitigt. Intensiviert sich einerseits im Gefolge des zweiten Abendmahlsstreits und der Auseinandersetzung mit Berengar von Tours die theoretische Diskussion des Messopfers und der Wandlung, so verbreitet sich andererseits die praktische Verehrung von Hostie und Eucharistie. ${ }^{34}$ Ohne die subtilen Nuancierungen im Einzelnen aufzurollen, kann man feststellen: Vor dem Horizont der Frage nach Natur und Bedeutung, Text und Exegese, Logik und Hermeneutik $^{35}$ entwickelt sich die Vorstellung einer substanzialen Gegenwart des Leibes Christi im Abendmahl, die sich weder in einem materiell-realistischen noch einem spirituell-symbolistischen Verständnis erschöpft. Vielmehr wird der kommemorative Charakter des Eucharistiegeschehens als ein Ineinander

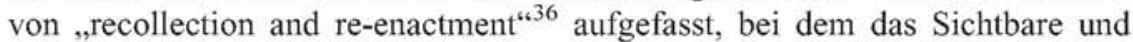
das Unsichtbare, das Sinnliche und das Übersinnliche, das Konkrete und das Übertragene zwar kategorial zu trennen sind, im Mysterium aber verschmelzen. Dieses zugleich christologische und ontologische Mysterium wird als Sakrament, bezogen auf das corpus mysticum der Kirche, und als Transsubstantiation institutionalisiert. ${ }^{37}$ Zwar blieb der Begriff der transsubstantiatio noch

33 Zum Kontrast zwischen (späteren) Fronleichnamsspielen und Passionsspielen im Hinblick auf die Darstellung des gemarterten Körpers WARNING (Anm. 12), S. 220-224.

34 KARL ADAm: Die Eucharistielehre des hl. Augustinus, Paderborn 1908; Hans JoRISSEN: Die Entfaltung der Transsubstantiationslehre bis zum Beginn der Hochscholastik, Münster 1965 (Münsterische Beiträge zur Theologie 28/1); KENNETH PLOTNIK: Hervaeus Natalis OP and the Controversies over the Real Presence and Transsubstantiation, München u.a. 1970 (Veröffentlichungen des Grabmann-Instituts N. F. 10); JEAN DE MONTCLOS: Lanfranc et Bérengar. La controverse eucharistique du $\mathrm{XI}^{\mathrm{e}}$ siècle, Louvain 1971; zusammenfassend: LUDWIG HöDL: ,Abendmahl, Abendmahlsstreit'. In: Lexikon des Mittelalters, Bd. 1, München 1980, Sp. 2227; seitdem GARY MACY: The Theologies of the Eucharist in the Early Scholastic Period. A Study of the Salvific Function of the Sacrament According to the Theologians c. 1080-1220, Oxford 1984; MIRI RUBIN: Corpus Christi. The Eucharist in Late Medieval Culture, Cambridge 1991; GARY MACY: Treasures from the Storeroom. Medieval Religion and the Eucharist, Collegeville/Minnesota 1999; STEPHAN WINTER: Eucharistische Gegenwart. Liturgische Redehandlungen im Spiegel mittelalterlicher und analytischer Sprachtheorie, Regensburg 2002 (Ratio fidei 13).

35 Vgl. BRIAN STOCK: The Implications of Literacy. Written Language and Models of Interpretation in the Eleventh and Twelfth Century, Princeton, New Jersey 1983, S. 252-315.

36 Hier S. 315.

37 4. Laterankonzil, Canon 1 (HeInRICh Denzinger/Peter HünermanN: Enchiridion Symbolorum, Nr. 800): Una vero est fidelium universalis Ecclesia, extra quam mullus omnino salvatur, 
lange unscharf und von einer Dogmatisierung, die die moderne Forschung gerne annahm, weit entfernt, doch kam es zweifellos zu einer Verfestigung, die allen fortdauernden theoretischen Kontroversen zum Trotz den Hintergrund bildet für die pragmatische Ausgestaltung von Messe und Kult sowie die ekstatische Vergegenständlichung in Mystik und Spiritualität. ${ }^{38}$ Die eine wie die andere setzen auf den doppelten Charakter einer Präsenz, die sowohl Anwesenheit (räumlich) wie Gegenwärtigkeit (zeitlich) verheißt und in gleichem Maße, in dem sie die äußeren Sinne anspricht, auch die inneren zur Verfeinerung bringen muss.

Die Wirksamkeit dieser Dialektik von Verkörperlichung und Verinnerlichung ist, blickt man auf die Entwicklung der Frömmigkeit in den folgenden Jahrhunderten, kaum zu überschätzen. In direktem Austausch stehen Formen der Meditation, die der Hinführung auf eine eindringliche Erfahrung des Übersinnlichen dienen, und solche der Vision, die diese in imaginativer Nähe präsent machen. Ebenso verbindet sich die Darlegung der dogmatischen, logischen und liturgischen Dimensionen des Eucharistiesakraments mit einer Materialisierung des ihm Zugrundeliegenden: des Körpers des Gottessohnes, der in Eucharistiemirakeln oder Hostienvisionen gegenständlich wird und damit zugleich die Memoria des Urbildes mit dessen Energie auflädt. ${ }^{39}$ Auch im geistlichen Spiel finden sich Momente der Zeugenschaft (die Mittelbarkeit implizieren) Seite an Seite mit Momenten der Erscheinung (die dem Abwesen-

in qua idem ipse sacerdos est sacrificium lesus Christus, cuius corpus et sanguis in sacramento altaris sub speciebus panis et vini veraciter continentur, transsubstantiatis pane in corpus, et vino in sanguinem potestate divina: ut ad perficiendum mysterium unitatis accipiamus ipsi de suo, quod accepit ipse de nostro. Vgl. HENRI DE LUBAC: Corpus Mysticum. Eucharistie und Kirche im Mittelalter. Eine historische Studie, Einsiedeln 1969.

38 Vgl. MACY (Anm. 34), S. 81-120; „The ,Dogma of Transsubstantiation“ in the Middle Ages“; begriffsgeschichtlich MATTHIAS LAARMANN: Transsubstantiation. Begriffsgeschichtliche Materialien und bibliographische Notizen. In: Archiv für Begriffsgeschichte 41 (1999), S. 119-150. Zur Eucharistieverehrung PETER BROWE: Die Verehrung der Eucharistie im Mittelalter, München 1932; CAROLINE WALKER BYnum: Holy Feast and Holy Fast. The Religious Significance of Food to Medieval Women, Berkeley, Los Angeles, London 1987; G[ODEFRIDUS] J. C. SNOEK: Medieval Piety from Relics to the Eucharist. A Process of Mutual Interaction, Leiden 1995; BARDO WEISS: Ekstase und Liebe. Die Unio mystica bei den deutschen Mystikerinnen des 12. und 13. Jahrhunderts, Paderborn u.a. 2000; HeIKE SCHLIE: Bilder des Corpus Christi. Sakramentaler Realismus von Jan van Eyck bis Hieronymus Bosch, Berlin 2002; ESTHER WIPFLER: ,Corpus Christi ${ }^{*}$ in Liturgie und Kunst der Zisterzienser im Mittelalter, Münster 2003; ANTJE WILLING: Literatur und Ordensreform im 15. Jahrhundert. Deutsche Abendmahlsschriften im Nürnberger Katharinenkloster, Münster 2004 (Studien und Texte zum Mittelalter und zur frühen Neuzeit 4).

39 Peter Browe: Die eucharistischen Wunder des Mittelalters, Breslau 1938 (Breslauer Studien zur historischen Theologie N. S. 4); die verstreuten Aufsätze zum Thema sind jetzt gesammelt in: DERS.: Die Eucharistie im Mittelalter. Liturgiehistorische Forschungen in kulturwissenschaftlicher Absicht. Mit einer Einführung hrsg. von HUBERTUS LUTTERBACH/THOMAS FLAMMER, Münster 2003 (Vergessene Theologen 1). 
den Anwesenheit verleihen): hier das Vorzeigen des Leichentuchs im leeren Grab, dort das Auftreten des Erlösers vor Maria Magdalena und den Jüngern. ${ }^{40}$ Sosehr das zweite Moment die körperliche Evidenz schafft, die dem ersten fehlt, sosehr bleibt es prekär. Es knüpft die Evidenz an historische Zeugen, mit denen auch die Evidenz selbst eine historische wird, die in späterer Zeit zusätzlicher Modi der Geltungsstiftung bedarf. Zu solchen Modi gehört die Re-Inszenierung der Ursprungssituation im Spiel. Sie stellt die Evidenz neu her, steht aber ihrerseits in der Gefahr, als künstliche Evidenz angesehen zu werden. So verliert denn auch das Erscheinen des Auferstandenen, von einer Figur dargestellt, seinen Als-ob-Charakter nur dort, wo es transzendiert wird auf das hin, an dem die Liturgie aufgrund des im Sakrament verkörperten ,Kontrakts der Realpräsenz' eine Teilhabe vermitteln kann. Die Kehrseite des Verlangens nach Präsenz ist also die Notwendigkeit von Absenz, die dem, was geglaubt wird, erst die Basis verleiht, auf der geglaubt werden kann.

Die Etablierung des Fronleichnamsfestes markiert, so gesehen, auch die Schwelle, an der die Vermehrung der Heilspräsenzen mit einer Kontrolle ihrer Grundlagen einhergeht. Die Durchdringung von Präsentischem und Dogmatischem erhält einen Ort im kirchlichen Festkalender. Das Fest feiert nicht nur die commemoratio der ursprünglichen Mahlgemeinschaft, sondern auch schon deren institutio durch die kirchliche Liturgie. ${ }^{41}$ Es reagiert auf die Probleme einer als solche unmöglichen Präsenz, indem es die Unmöglichkeit in Paradoxien verwandelt, in denen die Präsenz des Unmöglichen aufscheint. Es schafft selbstreflexive performative Möglichkeiten der Heilsinzenierung und bindet sie zugleich neu an die (jeweilige) kirchliche Praxis. ${ }^{42}$ Schon der Ursprungsmoment des Festes knüpft sich an die Paradoxie, dass derjenige, den es feiert, es selbst initiiert. Auf etwa 1208/09, wenige Jahre vor der Aussage zur Transsubstantiation seitens des vierten Laterankonzils, fallen in der Vita der ganz der Eucharistiefrömmigkeit ergebenen Nonne Juliana von Cornillon (Lüttich) die Visionen, in denen die Einführung eines Festes zur Feier des Altarsakraments durch Christus selbst autorisiert wird: Er deutet einen Flecken auf dem strahlenden Mond als Zeichen des Fehlens eines Kirchenfestes. ${ }^{43}$ Die Vision

40 Zur Verschiebung von der, inszenierten Absenz' zur, inszenierten Präsenz' Petersen (Anm. 11), pass.; generell zu den Ambivalenzen im Hinblick auf den abwesend-anwesenden Körper RAINER WARNING: Auf der Suche nach dem Körper. Das Imaginäre des geistlichen Spiels. In: Ritual und Inszenierung. Geistliches und weltliches Drama des Mittelalters und der frühen Neuzeit. Hrsg, von HANS-JOACHIM ZIEGELER, Tübingen 2004, S. 343-359.

41 Josef A. Jungmann: Missarum Sollemnia. Eine genetische Erklärung der römischen Messe, 2 Bde. 5., verb. Aufl., Freiburg i. Br. u.a. 1962, hier Bd. 1, S. 161.

42 Vgl. zum Folgenden die Beiträge von PETER BROWE: Die Entstehung der Sakramentsprozessionen; Die Elevation in der Messe; Die Ausbreitung des Fronleichnamsfestes. In: DERS.: Die Eucharistie im Mittelalter (Anm. 39), S. 459-536; RUBIN (Anm. 34); zusammenfassend ANGELUS HÄUSSLING: ,Fronleichnam*. In: Lexikon des Mittelalters, Bd. 4, München 1989, Sp. $990 \mathrm{f}$.

43 RUBIN (Anm. 34), S. 170. 
schafft die Urkunde, auf deren Basis in der Folgezeit Bedeutungen und Implikationen dessen, was sich in der Messe performativ vollzieht, ihrerseits performativ entfaltet werden. Die bekannten Stationen der Entwicklung sind: 1247 der Lütticher Bischof Robert ordnet das Fest für seine Diözese an; 1252 - der Kardinallegat Hugo von St. Cher schreibt es für seinen Legationsbereich vor; 1264 - Urban IV. macht es, die erste Festeinführung durch einen Papst, für die ganze Kirche verbindlich und stellte es den höchsten Festen gleich; 1311/12 Clemens V. erneuert die Vorschrift; 1317 - das Dekret wird in das Corpus Iuris Canonici aufgenommen. In der Folgezeit erlangt das Fest, verbunden mit einer Prozession, allgemeine Verbreitung, zunächst in den Diözesen des Reichs, dann auch in den romanischen und nördlichen Ländern.

\section{III}

Der Innsbrucker Spieltext steht also noch recht am Anfang einer Traditionsbildung, die im 15. Jahrhundert zu umfangreichen Dramatisierungen der ganzen Heilsgeschichte führen wird. ${ }^{44} \mathrm{Er}$ steht andererseits in verschiedenen Traditionslinien, die in den 756 Versen und 31 Reden zusammenlaufen. Beginnend mit Adam und Eva, fortfahrend mit zwölf Propheten und den zwölf Aposteln, Johannes dem Täufer und den Heiligen Drei Königen und schließend mit dem Papst eröffnet das Spiel eine Reihe bekannter Situationen. Mit den freudigen Reden Adams und Evas ist der Descensus aufgerufen. Die Wechselreden der Propheten und Apostel greifen auf Prophetenspiele zurück, die ihrerseits wie zahlreiche Darstellungen an und in Kirchen den pseudo-augustinischen Sermo Contra Judaeus, Paganos et Arianos benutzen. Auch die Aufteilung einzelner Sätze des Credo auf die Apostel ist geläufig. Die Gesänge der Propheten sind in der Liturgie verankert. Die Partien Johannes des Täufers und der Heiligen Drei Könige knüpfen an entsprechende Spieltypen an. Nur die Schlussrede des Papstes, die auf die eigentliche Anbetung der Hostie hinführt, stammt aus dem genuinen Kontext des Corpus-Christi-Festes. Mit ihr rundet sich der Bogen, der über zentrale Punkte der Heilsgeschichte, Sündenfall, Passion, Geburt Christi, in das Dogma der Transsubstantiation mündet.

44 Zum Überblick: Wolfgang FrIEDrich MiChaEL: Die Geistlichen Prozessionsspiele in Deutschland, Baltimore, Göttingen 1947 (Hesperia. Studies in Germanic Philology 22); THEO STEMMLER: Liturgische Feiern und geistliche Spiele. Studien zu Erscheinungsformen des Dramatischen im Mittelalter, Tübingen 1970 (Anglia. Buchreihe 15); ELIZABETH WAINWRIGHT: Studien zum deutschen Prozessionsspiel. Die Tradition der Fronleichnamsspiele in Künzelsau und Freiburg und ihre textliche Entwicklung, München 1974 (Münchener Beiträge zur Mediävistik und Renaissance-Forschung 16); SARAH BECKWITH: Signifying God. Social Relation and Symbolic Act in the York Corpus Christi Plays, Chicago, London 2001. Speziell zum Innsbrucker Spiel DORA FrANKE: Das Innsbrucker Fronleichnamsspiel, Diss. Marburg 1922; BERND Neumann: ,Innsbrucker Fronleichnamsspiel'. In: Die deutsche Literatur des Mittelalters. Verfasserlexikon. Zweite, völlig neu bearbeitete Aufl., Bd. 4, Berlin, New York 1983, Sp. $398-400$. 
Im Vordergrund steht solchermaßen die Vermittlung exemplarischer Aspekte der Heilsgeschichte, nicht deren Dramatisierung in einem Handlungsablauf. Schon das formelhafte Ich binz bei der Vorstellung der Apostel und Propheten schwankt zwischen Selbstpräsentation und Autoritätskonstitution. Zwar sind die Monologe der Apostel und anderer Figuren auf die vorangehenden der Propheten bezogen, im ganzen aber gewinnen die Reden ihre Dynamik vor allem durch die Spannung zwischen den verschiedenen Stufen von Zeitlichkeit, den verschiedenen Formen von Gegenwärtigkeit und den verschiedenen Momenten des Heilsgeschehens. Miteinander verflochten werden eine historische, eine heilsgeschehentliche und eine liturgische Zeitlichkeit. Einerseits sind die mit Christus verbundenen Ereignisse in einer Chronologie ab initio mundi fixiert: Adam spricht von 5100, Amos von 5200 Jahren bis zum Kommen des Messias, Jesaias datiert den Moment seiner Offenbarung auf 3500 Jahre vor dessen Geburt. Andererseits ist immer wieder das Ganze der Heilsgeschichte im Blick: Mit Adam wird der Sündenfall aufgerufen, mit Johannes eine ausführliche Erzählung der Kreuzigung eingespielt, mit Philippus ein Ausblick auf die Endzeit geboten. Jeweils findet dabei auch ein Brückenschlag zur aktuellen Situation statt: In Adams Rede verschiebt sich das „Wir“ der Vorväter zum „Wir“ der christlichen Gemeinschaft, der Bericht des Johannes wird eingeleitet mit der Anrede $\mathrm{Nu}^{e}$ horet ir frawen und man (IF V. 185), die Ausmalung des Jüngsten Gerichts durch Philippus schließt mit der Aufforderung: $n u^{e}$ hebit alle uf uwir hende / und bittet unsern hern Jhesu Crist, / der da kegenwertig ist, daz er ez thon dorch alle sin güte / und uns vor sulchem leyde behüte (IF V. 398-402). Auch sonst kommt es zu Überblendungen zwischen Vergangenheit und Gegenwart: Johannes Baptista blickt auf die Taufe Christi als vergangene zurück und verweist gleichzeitig auf das Lamm Gottes als gegenwärtiges. Die Propheten sprechen in der Vergangenheit, doch im Wechsel mit den auf die Gegenwart Christi bezogenen Aposteln, die wiederum in dem zwischen Präsens und Präteritum wechselnden Credo die geschichtlichen Ereignisse zu gegenwärtigen macht: gegenwärtig für die $\mathrm{Ge}-$ meinschaft in der rituellen Memorierung. ${ }^{45}$

Das Fronleichnamsspiel gleicht damit in seiner Grundstruktur einem Weihnachtsspiel wie dem Erlauer, das ebenfalls die Heilsereignisse nicht eigentlich darstellt, sondern nur evoziert, gerade aber im Bezug auf das Vorausgesetzte eine Engführung von vergegenwärtigtem und vergegenwärtigendem Geschehen ermöglicht. ${ }^{46}$ Mit dem Credo kommt gleich eingangs jenes Stück ins Spiel, das sich zwischen Wortgottesdienst und eucharistischer Liturgie situiert

45 Vgl. schon LUDWIG WolfF: Die Verschmelzung des Dargestellten mit der Gegenwartswirklichkeit im geistlichen Drama des deutschen Mittelalters. In: DVjs 7 (1929), S. 267-304; wieder in: DERS.: Kleinere Schriften zur altdeutschen Philologie, Berlin 1967, S. 319-349.

46 Zu Verbindungen zwischen den Spieltypen DORETTE KRIEGER: Die mittelalterlichen deutschsprachigen Spiele und Spielszenen des Weihnachtsstoffkreises, Frankfurt a.M., Bern 1990 (Bochumer Schriften zur deutschen Literatur 15). 
und die zunächst ,nur bruchstückhaft vorgetragene Frohbotschaft um den Zusammenhang der gesamten Heilsgeschichte" erweitert - eine Heilsgeschichte, die „den Glaubenden angesichts der eucharistischen Gegenwart erinnernd vor Augen" gestellt wird. ${ }^{47}$ Das Credo verkörpert also selbst schon jene konzentrierte Universalität, um die es im ganzen Spiel geht. Und so wie seine Einheit durch Verteilung auf die Apostel eine überindividuelle und überhistorische Glaubensgemeinschaft erzeugt, so erzeugt umgekehrt die Vielheit der Gesänge eine überindividuelle und übertemporelle liturgische Gestimmtheit. Die Gesänge gehen jeweils den Reden der Propheten voran. Sie vermitteln zwischen der Faktizität des Credo und der Prophetizität der Visio, zwischen Augenzeugenschaft und Seherschaft, zwischen christologisch bestimmter Institution und typologisch fundierter Providenz. Sie unterstreichen die Feierlichkeit des prophetischen Wissens und überführen dieses zugleich in liturgische Praxis. Die Gesänge basieren überwiegend auf jenen alttestamentlichen Stellen, die traditionell auf Christus hin gelesen wurden, begegnen aber im Rahmen des Spiels als neukontextualisierte ,Zitate', die zentrale liturgische Momente des kirchlichen Festkreislaufs aufrufen. Hier eine Übersicht im Hinblick auf mögliche Verwendungszusammenhänge im Rahmen der Messe und des Kirchenjahrs, unter Absehung der Tagzeiten und der vielfältigen regionalen Unterschiede:

\begin{tabular}{lllll}
\hline FIGUR & INCIPIT & $\begin{array}{l}\text { GESANG (CAO-NR.) } \\
\text { MESSE }\end{array}$ & LitURGISCHES JAHR & BIBEL \\
\hline Adam & Advenisti & $\begin{array}{l}\text { aus Antiphon Cum rex } \\
\text { gloriae }\end{array}$ & Osterfeier & \\
\hline Jeremias & & & & \\
\hline David & Dominus dixit ad me & Antiphon 2406, Introitus & Weihn./Vig. Epiph. & Ps 2,7 \\
\hline Jesaias & Ecce virgo concipiet & $\begin{array}{l}\text { Antiphon 25557/6620, } \\
\text { Communio }\end{array}$ & Verkündigung & Is 7,14 \\
\hline Daniel & $\begin{array}{l}\text { Sicut ovis ad } \\
\text { occisionem }\end{array}$ & Respons. 7661 & Karfreitag & Is 53,7 \\
\hline Hosea & O mors ero mors tua & Antiphon 4045 & Karsamstag & Os 13,14 \\
\hline Amos & $\begin{array}{l}\text { Ascendo ad patrem } \\
\text { Antiphon 1493 }\end{array}$ & Himmelfahrt & Io 20,17 & \\
\hline Johel & Dies irae dies illa & Sequenz & Totenmesse & \\
\hline Aggaeus & $\begin{array}{l}\text { Veni sancte spiritus } \\
\text { reple }\end{array}$ & Antiphon, Alleluia & Pfingsten & \\
\hline
\end{tabular}

47 NeUHeuser (Anm. 18), S. 122.

48 RENÉ-JEAN HESBERT: Corpus antiphonalium officii, Rom 1963-1979 (Rerum ecclesiasticarum documenta. Series maior. Fontes 7-12). 


\begin{tabular}{lllll}
\hline FIGUR & INCIPIT & $\begin{array}{l}\text { GESANG (CAO-NR.) / } \\
\text { MESSE }\end{array}$ & LITURGISCHES JAHR & BIBEL \\
\hline Sophonias & Locus iste & Antiphon, Graduale & Kirchweih & Gn 28,17 \\
\hline Malachias & Misereris omnium & Introitus & Aschermittwoch & Sap 11,24 \\
\hline Zacharias & Redemptor meus vivit & Antiphon 6348 & Totenmesse & Iob 19,25 \\
\hline Abdias & Venite benedicti & Introitus & Mittw. nach Ostern & Mt 25,34 \\
\hline Johann. d.T. & Ecce agnus dei & $\begin{array}{l}\text { Antiphon 2523/ } \\
\text { Respons. 6575 }\end{array}$ & Weihnachten & Io 1,29 \\
\hline
\end{tabular}

Die Gesänge entsprechen nicht dem, was man als Liturgie des Fronleichnamsfestes kennt, die sich ihrerseits an der Karfreitagsmesse orientiert und als rememorative Feier des Abendmahls versteht. Zum Beispiel fehlt die bekannte, von Thomas von Aquin stammende Sequenz Lauda Sion, die bald schon als Quintessenz des Corpus-Christi-Gedankens aufgefasst wurde. ${ }^{49}$ Auch orientiert sich die Folge der Antiphonen und Responsorien, mit Ausnahme der zentral plazierten Sequenz Dies irae, nicht am Aufbau der Messe; weder die Perikopen zum Gründonnerstag noch jene zu Fronleichnam scheinen auf. ${ }^{50}$ Statt dessen konzentrieren die Gesänge das Kirchenjahr und die sich zwischen Weihnachten, Ostern und Pfingsten abspielende Bewegung des Heilsgeschehens auf das Fest zu Ehren des Corpus Christi. Und sie unterstreichen damit seinen Charakter als Überhöhung des christlichen Kults durch Ausrichtung auf das Dispositiv der Eucharistie. Vereint sich in diesem Dispositiv brennspiegelartig, was die Verknüpfung von sacrificium und eucharistia, von Göttlichkeit und Menschlichkeit, von Heilsverlust und Heilsgewinn ausmacht, so vereint sich im Spiel, was sonst aspekthaft auseinander tritt: Verkündigung, Geburt, Passion, Auferstehung und Himmelfahrt des Erlösers. Schon in den einzelnen Gesängen und den ihnen zugrundeliegenden Bibelstellen kommt es zu Überblendungen der Zeitstufen. Der Verweis auf eine Jungfrauengeburt bei Jesaias ist eine alttestamentliche Prophezeiung, die im Neuen Testament ( $\operatorname{Lc} 1,31)$ so aufgegriffen wird, dass das eine präsentische ecce im anderen sein Echo findet und dieses Echo als im Ausgangswort impliziert gilt:

Die Gegenwart wird an die Zukunft gebunden, an eine Zukunft indes, die in Form einer Prophezeiung bereits in einer fernen Vergangenheit ausgesprochen und nieder-

49 DAVID Berger: Thomas von Aquin und die Liturgie, Köln 2000; JAN-Heiner Tück: Die Sequenz Lauda Sion als poetische Verdichtung der Eucharistietheologie des Thomas von Aquin. In: Theologie und Glaube 93 (2003), S. 475-497; zu deutschsprachigen Versionen JOHANNES JANOTA: Studien zu Funktion und Typus des deutschen geistlichen Liedes im Mittelalter, München 1968 (MTU 23), S. 211-215.

50 Vgl. zu diesen Perikopen YuMI DoHI: Das Abendmahl im spätmittelalterlichen Drama. Eine Untersuchung der Darstellungsprinzipien der Abendmahlslehre in den englischen Mystery Cycles und ihren Vorlagen im Vergleich mit den französischen und den deutschsprachigen biblischen Spielen, Frankfurt a.M. 2000 (EHS XVIII,95), S. 65-69. 
geschrieben worden war. Doch damit nicht genug. Das Futurum ist zugleich ein Quasi-Performativ, das concipies wird ausgesprochen, um in der Gegenwart eine Wirkung zu zeitigen. Denn ein fast unmittelbares Echo - das ecce der Jungfrau wird genügen, damit sogleich der Leib Christi im Schoß Marias empfangen wird. ${ }^{51}$

Im Spiel wiederum wird dadurch eine Form der Inszenierung von Präsenz möglich, die nicht auf mimetischer, sondern auf symbolischer Verkörperung beruht und doch, um dem Symbolischen Evidenz zu verleihen, mit dem Mimetischen als Möglichkeit operiert. Das zeigt sich an der Präsenz des Gottessohnes. Christus tritt nicht auf und ,steht" doch im ,Raum. Er ist als sprechende und handelnde Figur abwesend und doch als Grund und Ziel des Vorgeführten anwesend. Adam, selbst im furburge der hellen (IF V. 12) befindlich, ,sieht" ihn eingangs an jenem unbestimmten ,dort", das mit den Pforten der Hölle assoziiert werden kann, geht doch die Advenisti-Antiphon im Rahmen des Cum rex gloriae der Osterfeier dem Atollite portas voran. ${ }^{52}$ Auch Thomas ,sieht' ihn später dort an eyner stat / als er für czu der helle (IF V. 280 f.). Eva dankt ihm, dass er vom Himmel herabgekommen sei und Licht in die Finsternis gebracht habe. Verschiedene der Propheten und Apostel ,sehen“ ihn. Johannes der Täufer verweist auf ihn als das Lamm Gottes (Ecce agnus dei). Caspar äußert seine Dankbarkeit, dass sein Wunsch, das kindelin zu sehen, nunmehr in Erfüllung gegangen sei.

Christus ist also präsent in den signifikanten Bildern seiner Existenz: als König, der die Welt beherrscht, als Triumphator, der den Tod überwindet, als Lamm Gottes, das die Schuld hinwegnimmt, als Kind, das Mensch geworden ist - wobei schon die achronologische Folge der Bilder darauf verweist, dass diese Präsenz nicht im Sinne eines empirischen Jetzt zu verstehen ist. Da zu sein als imago heißt gleichzeitig nicht und doch da zu sein als corpus: nicht im Sinne einer Figur, doch im Sinne einer Realität, die sich in der Hostie manifestieren soll. Sie jedoch wird nicht einfach als abstrakte Form der Realpräsenz ins Spiel gebracht, sondern durch die Erscheinungsformen des abwesend-anwesenden Christus mit dessen Geschichte und Gegenwärtigkeit aufgeladen. ${ }^{53}$ Deshalb ist zwar verschiedentlich auf das Sakrament verwiesen: David meint Christus in seiner Heimlichkeit zu sehen - verborgen in eynes brotes schin, / doch sult ir des sicher sin, / da ist werlich fleysch und blut (IF V. 145-147); Caspar erkennt ihn in dez priesters henden (IF V. 591). Doch die eigentlichen Konturen der Hostie bleiben im Ungewissen - so wie auch Thomas von Aquin in seiner Auslegung der Einsetzungsworte auf den unbestimmten Charakter des hoc in hoc est corpus meum verwiesen hatte: „ein Pronomen

51 DiDi-Huberman (Anm. 16), S. 121.

52 So auch im Innsbrucker Osterspiel; vgl, die Edition von MONE (Anm. 29), Regieanweisung nach V. 204; Adam stellt dann fest: ich sehe den, der mich geschaffen hat, / an dem hymmel und erde stat; zur Rolle des Canticum triumphale in den Osterspielen THORAN (Anm. 7), S. 186-195.

53 Zur Verschränkung von Absenz und Präsenz v.a. BECKwITH (Anm. 44), Kap. 5. 
wird gebraucht, das die Substanz in unbestimmter Weise bezeichnet und ohne festgelegte Form lässt“" ${ }^{54}$

Auch die Schlussrede des Papstes legt diese Form nicht fest. Sie betont die Differenz zwischen dem alttestamentlichen Manna und der neutestamentlichen Hostie: Diente das eine konkret der irdischen Ernährung, so dient die andere realsymbolisch der überirdischen Heilsvermittlung; war die Existenz des einen kurzfristig und trügerisch, so ist die der anderen ewig und wahrhaftig. ${ }^{55}$ Auf diese Weise kommt die bekannte Figur einer Erfüllung des Vorläufigen zum Tragen: Was Schrift war, ist nun Vollzug, was Gleichnis war, ist nun Zeugnis, was von einigen gesehen werden konnte, kann nun von allen aufgenommen werden. Auch der typologische Bezug zwischen Adam und Christus lässt sich in der Metaphorik des Essens fassen: Was dem einen der fatale Apfelgenuss verwirkte, ist durch den freudvollen Genuss der neuen Speise, die der andere bewirkte, überwunden. Doch bleibt der Text nicht bei der kontrastiven Profilierung stehen, er betreibt auch eine performative Aufladung der eucharistischen Gegenwart. Sie soll als eine erscheinen, die nicht nur die fehlende Körperlichkeit der Hostie kompensiert, sondern auch die (vermiedene, aber mitgedachte) mimetische Körperlichkeit des Messias in eine Sinnlichkeit neuer und anderer Art transformiert. Für diese Sinnlichkeit spielt die Sprache eine wichtige Rolle. Im Wort vollzieht sich eine Beschwörung dessen, was man der Hostie per se nicht ansehen kann:

daz ist an sußekeit ungemeßen

und ist lustig $\mathrm{czu}^{\mathrm{c}} \mathrm{e}$ en,

daz ist das edele eßen,

daz den hymmel hat beseßen,

daz ist das edele eßen,

des wir an dem leczten nymmer schullen vorgeßen,

ich meyne daz onschuldige lam,

gotes froner lichnam.

(das ist unermesslich in seiner Süße und ist angenehm zu verspeisen, es ist eine edle Speise, die den Himmel in sich schließt, es ist eine edle Speise, die wir am Ende nie vergessen dürfen, ich meine das unschuldige Lamm, Gottes hehrer Leib; IF V. 717-724).

54 Thomas von AQuin: Summa Theologiae (Editiones Paulinae), Alba, Rom 1962, Tertia pars, qu. 78, a. 5: Et ideo signanter non dicit Dominus, , Hic panis est corpus meum; quod esset secundum intellectum secundae opinionis; neque, ,Hoc corpus est corpus meum; quod esset secundum intellectum tertiae; sed in generali, ,Hoc est corpus meum; nullo nomine apposito ex parte subiecti, sed solo pronomine, quod significat substantiam in communi sine qualitate, id est forma determinata.

55 Ähnlich auch am Ende der Lauda Sion-Sequenz: In figuris praesignatur, / Cum Isaac immolatur; / Agmus Paschae deputatur, / Datur manna patribus (Josef Dirnbeck: Hymnen der Kirche. Lateinische Texte und deutsche Nachdichtungen, Graz 1978, S. 118-123, und in vielen kirchlichen Gesangbüchern). 
Die Emphatisierung der Sprache bedarf der dogmatischen Rückbindung. Und so bleibt im Gestus der verbalen Feier deren theologische Basis präsent. Die Aura, die der Text um die Eucharistie zu schaffen sucht, entsteht aus der Verflechtung von Metapher und Metonymie: Brot, Lamm, Körper Christi - sie sind Ausdruck eines Transsubstantiationsgeschehens, das nicht nur die mögliche Wiederholung eines historischen Wunders meint, sondern die faktische in der Liturgie, die aber zu ihrer Bestätigung selbst die fortwährende Rückerinnerung an den Ursprung (vil lyben lute gedencket dar an; IF V. 695) einschließt. Die entscheidende Pointe dieser Rückerinnerung besteht aber darin, sie zugleich auf die Institution selbst zu beziehen, die damit als historische mit ihrem Ursprung weniger durch Analogie als durch Kontiguität verbunden ist. Die Einsetzungsworte hoc est corpus meum wiederholen, in der Messe gesprochen, einerseits das Momentum, aus dem sie herrühren, und erweisen andererseits durch den Zusatz hoc facite in meam commemorationem (Lc 22,20) die Wiederholung als selbst dem Momentum eingeschrieben. Die Wiederholung ist deshalb immer Übertragung und Aktualisierung in einem. Wenn in der Rede des Papstes die Einsetzung von Leib und Blut im letzten Abendmahl zitiert wird, kommt nicht nur der gottmenschliche Ursprung selbst zur Sprache. Es kommt auch die Größe ins Spiel, die die Transsubstantiation dem Gläubigen nachvollziehbar werden lässt - das Herz:

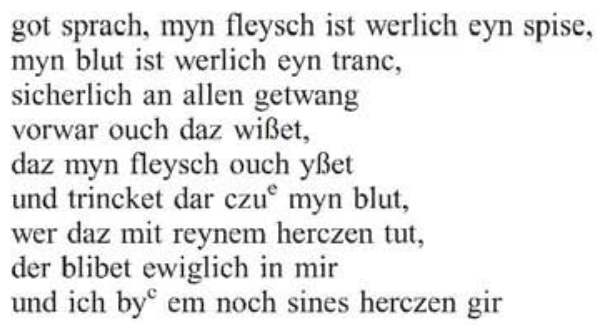

(Gott sagte: „mein Fleisch ist wahrlich eine Speise, mein Blut ist wahrlich ein Trank, für gewiss könnt ihr halten, dass wer auch immer mit reinem Herzen mein Fleisch zu sich nimmt und mein Blut trinkt, der wird immer in mir sein und ich in ihm - wie es sein Herz begehrt"; IF V. 728-735).

In der intensivierten Gegenwärtigkeit der Hostie kulminieren sowohl die dogmatischen wie die präsentischen Tendenzen des Fronleichnamsspiels. Einerseits wird mit der Figur des Papstes jene Instanz greifbar, die am Ursprung der Institution steht, welche eine neue Dimension eucharistischer Frömmigkeit ermöglicht. Andererseits geht das innere und äußere Sehen der zuvor aufgetretenen Propheten und Zeugen in jenes Verkosten und Vereinnahmen über, dessen intensive Erfahrung das Institut des Fronleichnamfestes erlaubt. Dieses Verkosten und Vereinnahmen soll aber seinerseits nicht als krude körperliches verstanden werden. Vielmehr unternimmt der Text alles, das Sinnliche von seiner bloßen Materialität zu befreien und gleichzeitig das Übersinnliche in 
materiellen Kategorien zugänglich zu machen. Aufgehoben werden Grenzen zwischen indexikalischen und symbolischen Zeichen ebenso wie solche zwischen Ereignis und Institution. Suggeriert wird die Möglichkeit eines realsymbolischen Zeichengebrauchs, der zwar ständig Bedeutungszuschreibungen benutzt, zugleich aber den Akt der Zuschreibung ontologisiert: Die verschiedenen Opfer, die die Heiligen Drei Könige dem kindelin darbringen, sind „symbolische Gaben“56 und zugleich uffbare zeichen (IF V. 598) - Zeichen der Evidenz und der Offenbarung, in denen das Bezeichnete selbst anwesend sein soll.

Das Spiel transzendiert sich selbst als Spiel - schon dadurch, dass es den Begriff des Spiels auf das Heilsgeschehen beschränkt: als hertes spil wird das Jüngste Gericht bezeichnet, als froliches spil die Auferstehung, als vorspil das Alte Testament. Auf diese Weise erhält das Dogma eine Gültigkeit, die scheinbar nicht an die Kontingenz des (volkssprachigen) Textes gebunden ist, obschon historisch gesehen gerade diese erkennen lässt, unter welchen Bedingungen ein Text Geltung, die ihm nicht selbstverständlich zukommt, entwerfen kann. Diese Bedingungen nämlich unterliegen historischem Wandel, wie sich an den späteren Fronleichnamsspielen zeigt: Das Künzelsauer Spiel etwa, obwohl es kirchlich-kultische Züge beibehält, weitet den heilsgeschichtlichen Rahmen auf die Ereignisse zwischen der Erschaffung der Engel und dem Jüngsten Gericht; es bringt ausführliche Darstellungen des Lebens Johannes des Täufers und der Passion; es fügt allegorische und katechetisch-moralische Szenen ein (Streit der Töchter Gottes, Streitgespräch zwischen Ecclesia und Synagoga, Streitgespräch zwischen Körper und Seele). ${ }^{57}$ Diese Vielfalt verwischt, was im Innsbrucker Spiel im Zentrum steht: die Faszination an der machtvollen Realsymbolik des Sakraments, die Anstrengung, den Verzicht auf mimetische Präsenz zu vergolden durch die Suggestion einer Omnipräsenz des Heils und des Erlösers in den Zeichen, Namen und Worten. So wie das in der Handschrift vorangehende Osterspiel nicht einfach mit den Erscheinungen des Auferstandenen schließt, sondern mit dem an das Publikum gerichteten Hinweis auf die Bedeutungshaftigkeit des Gesehenen und Gehörten (IO V. 1163), so zielt auch das Fronleichnamsspiel auf eine gegenwärtige Gemeinschaft, die sich ihrerseits von der reinen Sicht- zur höheren Glaubensgemeinschaft bewegt. In das durch das Alte Testament begründete und durch das Neue transformierte heilsgeschichtliche Bedingungsgefüge eintretend, bildet sie den Fluchtpunkt der einzelnen Szenen: implizit oder explizit angesprochen von den einzelnen Figuren, aufgefordert von Philippus zum Gebet (IF V. 398), von

56 Krieger (Anm. 46), S. 23.

57 Das Künzelsauer Fronleichnamspiel. Hrsg. von PETER K. LIEBENOW, Berlin 1969 (Ausgaben deutscher Literatur des XV. bis XVIII. Jahrhunderts. Reihe Drama II). Die Differenzen zeigen sich gerade auch dort, wo die Berührungen am stärksten sind, etwa bei der Umsetzung des Credos in den Apostelreden: V. 3844-4282 (Kommentar S. 282 f.). 
Johannes Baptista zum Gesang (IF V. 569 f.), vom Papst am Ende zum Kniefall (IF V. 747). Diese Gemeinschaft ist - wie der Interpretand der PEIRCEschen Zeichentheorie - das notwendige Dritte, in dem Signifikanten und Signifikate verbunden sind, konkret hier: in ihrer ontologischen Verbundenheit zur Erscheinung kommen.

\section{IV}

Es ist deutlich: Die performative Dimension des Innsbrucker Fronleichnamsspiels liegt weniger in der Aufführung einer Handlungsfolge wie im Falle der Oster- und Passionsspiele als vielmehr in der Durchführung einer Devotionsfolge wie im Falle der (späteren) katechetischen Bildtafeln. ${ }^{58}$ Es fehlen die Regiebemerkungen ebenso wie die Precursorpassagen, die sich in den beiden anderen Spielen der gleichen Handschrift finden. Keine Rolle spielen Bewegungen und Gesten. Und doch wird die Devotionsfolge nicht als statische, sondern als dynamische entworfen. Sie macht schon durch die Aufteilung des Credos auf die Apostel die Rememorierung des Glaubenskonzentrats zum stufenhaften Prozess und durch die Verflechtung der Apostel- und der Prophetenreden das Verhältnis von Providenz und Geschichte zum sich wiederholenden Vollzug. In ihm werden die Formen der Präsenz Christi, die auf der tatsächlichen Absenz seines Körpers beruhen, in eine Form der Präsenz der Hostie überführt, die zwar auf Anwesenheit beruht, sich aber zugleich in einem Mehr-als-nur-Sichtbaren aufhebt: Das Brot gilt als dasjenige, das, so unscheinbar auch äußerlich, die ganze Heilsgeschichte in sich fasst, die wiederum innerlich aus ihm entfaltet werden kann. Auch dem Osterspiel ist diese Verknüpfung von Zeigen und Sagen nicht fremd: Im direkt vorangehenden Innsbrucker Text folgt auf die Präsenz des Auferstandenen (vor Maria Magdalena und Thomas) die Evidenz seines Auferstandenseins - das Vorzeigen des Leichentuchs und der zwischen den handelnden Figuren und der christlichen Gemeinschaft vermittelnde Hinweis: Seht vil lyben daz thuch, / daz uns widerwant hat den fluch, / der uns in dem paradyse wart gegeben, / wir schullen alle mit gote leben (IO V. 1158-1161). Die Übertragung des Heilsgeschehens auf Objekte, die sie bezeugen, sichert, dass es Metonymien des Heils gibt, die sowohl die Zeiten überdauern wie je neu zur re- und kommemorativen Entfaltung des Ganzen der Heilsgeschichte genutzt werden können. Diese rememoratio und commemoratio aber basiert auf einer Performativität, die nicht mit derjenigen der mimetischen Aufführung identisch ist: eine innere Performati-

58 Hartmut Boockmann: Wort und Bild in der Frömmigkeit des späten Mittelalters. In: Pirckheimer-Jahrbuch 1985, S. 9-40; DERS.: Über Schrifttafeln in spätmittelalterlichen deutschen Kirchen. In: Deutsches Archiv für Erforschung des Mittelalters 40 (1984), S. 210-224; RUTH SLENCZKA: Lehrhafte Bildtafeln in spätmittelalterlichen Kirchen, Köln, Weimar, Wien 1998 (Pictura et poesis 10). 
vität, mit deren Hilfe ein Text wie das Innsbrucker Corpus-Christi-Spiel eine Intensität des Moments entwirft. Dieser Moment ist ein Vergangenheit, Gegenwart und Zukunft, Präsentation, Evokation und Signifikation engführendes ,ewiges $\mathrm{Nu}^{6}{ }^{59}$ In ihm soll sich die Leerstelle, um die der Text kreist, als Ort der Fülle erweisen und die Fülle wiederum als Wort manifestieren: als Wort, in dem sich die Zeugenschaft vollzieht und jene Verkörperung Ausdruck erhält, die dem Messias nicht selbst Ausdruck verleiht.

In seinem Explizit spricht der Schreiber namens Johannes nicht mehr wie im Incipit von einem ludus, sondern von einem lyber de corpore Christi. Das indiziert historische Abstufungen in den Graden dialogisch-dramatischer Inszenierung und nähert den Text den klassischen Schriften des ersten und zweiten Eucharistiestreites an, die unter Titeln wie Liber de corpore et sanguine domini liefen. ${ }^{60}$ Doch ist damit auch der Abschluss eines sich materialiter manifestierenden Buches bezeichnet, wie Johannes zunächst auch schon nach dem Explizit des Osterspiels (Explicit ludus de ressurectione domini) vermerkte: Completus est liber iste. Dieses Buch hat es nicht nur in seinem Abschlusspart, sondern seinen drei Teilen mit dem corpus Christi zu tun. Zwar stehen diese Teile in keiner originären Verbindung. Doch zumindest dem thüringischen Leser, Schreiber und Redaktor des Spätsommers 1391 wurden sie zum zusammenhängenden Komplex. Beginnend wahrscheinlich im Umkreis jenes Festtags, auf den sich das erste Spiel bezieht, Assumptio Mariae (15. August), schrieb Johannes kontinuierlich und dokumentierte seinen Schreibfortschritt durch sukzessive Datierungen: sabato die post Bartholomei (26. August), sexta feria in die Egidij (1. September), tertia die ante natiuitatis Marie virginis (5. September). ${ }^{61}$ Für ihn war wohl zum einen zumindest der Ausgangspunkt seines Schreibens mit dem Fest verbunden - dessen Feier wurde ihm, unabhängig davon, was der genaue Anlass gewesen sein und ob es eine Aufführung gegeben haben mag, in der Schrift zu seiner eigenen ,Aufführung؛ Für ihn waren zum andern auch die Texte miteinander verbunden: Von einer Stelle im Osterspiel, da die Grabwächter das Fehlen des Leichnams bemerken (f. $37^{\vee}$, IO V. 194), irrte er auf eine schon geschriebene Stelle des Spiels von Mariae Himmelfahrt ab, an der ebenfalls milites auftreten (f. $26^{\mathrm{v}}$, IHM V.

59 Vgl. auch zur ,inneren Aufführung CARLA DAUVEN-VAN KNIPPENBERG: Ein Schauspiel für das innere Auge? Notiz zur Benutzerfunktion des Wienhäuser Osterspielfragments. In: Ir sult sprechen willekomen. Festschrift für Helmut Birkhan zum 60. Geburtstag. Hrsg. von CHRISTA TUCZAY u.a., Bern u.a. 1998, S. 778-787; in musikwissenschaftlicher Hinsicht ULRIKE HASCHER-BURGER: Gesungene Innigkeit. Studien zu einer Musikhandschrift der Devotio Moderna (Utrecht, Universiteitsbibliotheek, Ms. 16 H 34, Olim B 113). Mit einer Edition der Gesänge, Leiden u. a. 2002.

60 Ein Justinian-Text in der Handschrift Cesena, Biblioteca Malatestiana, Nr. 167.135 (Papierhandschrift des 15. Jh.s) hat als Incipit tractatus de corpore Christi, als Explizit liber de corpore Christi.

$61 \mathrm{Zu}$ der daraus errechenbaren Schreibgeschwindigkeit: Neustifter-Innsbrucker Spielhandschrift (Anm. 29), S. 13. 
2864), und brauchte eine Weile, den Fehler zu erkennen - in seiner Memoria schlossen sich die Texte der einzelnen Lagen zusammen. ${ }^{62}$ Es schloss sich zusammen, was auch tatsächlich nicht ohne Verbindung ist: Das Osterspiel endet mit jenem Hinweis auf den Descensus Christi ad inferos, der im Fronleichnamsspiel in Adams Eröffnungsrede aufscheint. Das Spiel von Mariae Himmelfahrt beginnt wie das Fronleichnamsspiel mit den Aposteln, welche die einzelnen Sätze des Credo vortragen. Auch in ihm spielt das Moment der (predigthaften) Glaubensvermittlung eine zentrale Rolle. ${ }^{63}$

Anders als die Erlauer Spielehandschrift, die sich auf die Christusgeschichte konzentriert, ${ }^{64}$ bietet die Innsbrucker aspekthafte Entfaltungen der Heilsgeschichte: einmal vom biblischen Kernereignis der resurrectio her, einmal im Blick auf die Konstitutionsphase des frühen Christentum (Marientod, Mission, Zerstörung Jerusalems), einmal hinsichtlich der das Dogma in Liturgie überführenden Institutionalisierung des Fronleichnamsfestes. Jedes dieser Szenarien impliziert andere Typen der Präsenz Christi - gedacht wieder von der Mitte des Osterspiels her: hier die postmortale Körperlichkeit des Auferstandenen, der nochmals in menschlicher Form erscheint, dort die transfigurierte Gestalthaftigkeit des Aufgefahrenen, der in die irdische Geschichte eingreift, schließlich die transsubstantiierte Realfigürlichkeit dessen, der im Sakrament anwesend ist. Damit einher gehen verschiedene Formen von Memoria: eine christologische, eine ekklesiale, eine liturgische. Und verschiedene Ausprägungen von Performativität: eine handlungsbetonte (Vollzug der festgelegten Ereignisse bei Tod und Auferstehung Christi), eine gruppenbetonte (Bewegung zwischen den durch Maria, die Apostel, die Juden und die Heiden markierten

62 Die Hartnäckigkeit im Festhalten an dem gewählten Fortsetzungstext zeigt sich an dem mehrfachen Versuch, den richtigen Anschluss zu finden: Nach neun Versen bemerkte der Schreiber das Nicht-Zusammenpassende des Textes und wechselte zu einem wenig späteren Stück im Himmelfahrtsspiel (in der schon abgeschriebenen Lage ebenfalls ein Seitenbeginn), schrieb sieben Verse ab, sprang zur nächsten Regieanweisung, dann wieder zurïck, schrieb weitere zwölf Verse $a b$ und brach den Text schließlich mitten im Vers ab. Ein Neueinsatz mit der nunmehr richtigen Stelle erfolgte auf der Verso-Seite. Den Text auf der Recto-Seite strich der Schreiber durch und fügte non pertinet hinzu. Vgl. auch STEPHEN WRIGHT: Scribal Errors and Textual Integrity: The Case of Innsbruck Universitätsbibliothek Cod. 960. In: Studies in Bibliography 39 (1986), S. 79-92, hier $84 \mathrm{f}$.

$63 \mathrm{Zu}$ dem Text: STEPHEN Wright: The Vengeance of our Lord. Medieval Dramatizations of the Destruction of Jerusalem, Toronto 1989 (Studies and Texts 89), S. 33-67; Bernd NeumanN: Das Innsbrucker Spiel von Mariae Himmelfahrt. Gedanken zu einer Neuedition. In: Neue Beiträge zur Germanistik 1 (2002) [Internationale Ausgabe von „Doitsu Bungaku“ 109], S. 191206; gegen ein fragmentarisches Ende des Textes jetzt CORA DIETL: The Virgin, the Church and the Heathens. The Innsbruck Ludus de assumptione beatae Mariae virginis (2004), unter: http://parnaseo.uves/Ars/webelx/Ponències\%20pdf/Dietl.pdf.

64 Vgl. Johannes Janota: Zu Typus und Funktion der Erlauer Spielaufzeichnung. In: Die Österreichische Literatur. Ihr Profil von den Anfängen im Mittelalter bis ins 18. Jahrhundert (10501750). Hrsg. von Herbert Zeman, Bd. 1, Graz 1986, S. 511-520. 
Orten), eine symbolbetonte (Engführung der Zeiten und Momente des Heilsgeschehens in der Eucharistie).

Die Handschrift vereint ein Spektrum von Typen, dem wiederum ein Spektrum von rezeptiven Haltungen und performativen Dimensionen entspricht. Vielleicht bald nach Abschluss der Niederschrift der Spiele trug ein zweiter Schreiber, in seinen Graphien dem ersten ähnlich, auf der Rückseite des letzten Blattes des Fronleichnamsspiels einen längeren lateinischen Zauberspruch ein. ${ }^{65}$ In 56 Zeilen vermittelt dieser Spruch die Kenntnis, mit Hilfe des Eisenkrauts (Verbena) einen Liebeszauber auszuüben. In Dienst genommen werden dafür, wie häufig in Zaubersprüchen, Vaterunser, Credo und Beginn des Johannes-Evangeliums, außerdem die höchsten christlichen Instanzen und die ganze Schöpfung:

Ich beschwöre dich beim Vater, dem Sohn und dem Heiligen Geist, ich beschwöre dich Verbena, voll der Gnade, beim lebendigen Gott, beim heiligen Gott, beim wahren Gott, bei der heiligen Dreifaltigkeit und Einheit, der du der wahre dreieinige Gott bist, daß du mich erhörst und meine Befehle ausführst, ich beschwöre dich Verbena bei Gott, der dich geschaffen hat, bei der Erde, die dich trägt, bei der Sonne, die dich wärmt, beim Mond, den Sternbildern und den Gestirnen, die über dir leuchten, beim Wind, der dich bewegt, bei den Flüssen, die dich benetzen, beim Himmel der dich öffnet, und dem Abgrund, der dich stützt. ${ }^{66}$

Die Nähe zwischen profanen und religiösen magischen Praktiken ist nichts Ungewöhnliches. Sie begleitet die Überlieferung von Gebeten und Messformularen seit frühesten Zeiten. Schon in der ,„ältesten Handschrift des gelasianischen Sakramentars aus der Mitte des 8. Jahrhunderts gibt es Meßformulare zum Beispiel für Reisende, zur Erlangung von Liebe und Eintracht, gegen Beunruhigung und Tumult, gegen Sterblichkeit und Viehseuchen, für Regen oder Sonnenwetter, bei Sturm und Gewitter, am Geburtstag und mehr noch für den Sterbetag, bei Unfruchtbarkeit einer Frau oder bei Ablegung des Keuschheitsgelübdes einer Witwe“. Später dann begegnen „Meßfeiern nicht nur für Schwangere, sondern ebenso zur Liebesverzauberung, für eine glückliche Geburt, aber auch als Tötungszauber, gegen die Pest oder beim Gottesurteil.“67

65 WALTER NEUHAUSER: Eine unbekannte lateinische Beschwörungsformel in der sog. NeustifterInnsbrucker-Spielhandschrift (Cod. 960 der Universitätsbibliothek Innsbruck). In: Serta philologica Aenipontana 3, Innsbruck 1979 (Innsbrucker Beiträge zur Kulturwissenschaft 20), S. $221-253$

66 Ebd., S. 230 f., Z. 12-22: Coniuro te per patrem et filium et spiritum sanctum, coniuro te verbena Dei gracia plena per Deum vivum, per Deum sanctum, per Deum verum, per sanctam trinitatem et unitatem, qui verus Deus trinus et unus, ut modo audias me et facias me precepta, te verbena per Deum qui te creavit, per terram que te portat, per solem qui te calefacit, per lunam qui te movet, flumina que te irrigant, per celum quod te aperit et habissum qui te sustinet. $\mathrm{Zu}$ ähnlichen Reihen von Beschwörungen bei göttlichen und natürlichen Instanzen RICHARD KIECKHEFER: Forbidden Rites. A Necromancer's Manual of the Fifteenth Century, University Park, Pennsylvania 1998.

67 ARNOLD ANGENENDT: Geschichte der Religiosität im Mittelalter, Darmstadt 1997, S. 495, 497. 
Auch die volkssprachig-lateinischen Gebete und Benediktionen aus Muri (12. Jahrhundert) sind stark von sprachmagischen Zügen geprägt und enthalten unter anderem eine Formel zur Wiederherstellung ehelichen Liebesglücks. ${ }^{68}$ Der Eintrag des Zauberspruchs am Ende der Spielhandschrift ist insofern nicht ohne innere Logik. Auch hat die Verbindung zwischen dem Wunsch, in der Eucharistie, und dem, in der Liebesmagie göttlicher Unterstützung teilhaftig zu werden, in der Praxis der Zeit nichts Absurdes: Seit dem 12. Jahrhundert und verstärkt seit dem vierten Laterankonzil sind Beispiele für Liebeszauber mit Hilfe von Hostien bezeugt. ${ }^{69}$ In eine Handschrift des 14. Jahrhunderts wurde ein Text eingetragen, in dem sich die auf Tetragrammaton bezogene Beschwörung einer Wachspuppe mit derjenigen eines Krautes zum Liebeszauber verbindet. ${ }^{70} \mathrm{Im}$ frühen 15. Jahrhundert liefert das Buch der Heiligen Dreifaltigkeit sogar ein kühnes Beispiel für die Übertragung des Transsubstantiationsmodells auf eine sich in der Sprache vollziehende Alchemie. ${ }^{71}$

Zaubersprüche sind ebenso wie Gebete performative Texte par excellence. In ihnen ist das Sagen ein Tun, ein Vollziehen, ein Bewirken. Gleichzeitig bestimmen narrative Rahmenpartien häufig die Bedingungen und Gegebenheiten des auszuführenden Aktes. Sie schaffen damit Performativa zweiter oder (berücksichtigt man auch die Differenz zwischen Rede und Schrift) dritter Ordnung und ermöglichen eine Ausstellung des magischen Textes, die dessen Wirkung nicht aufhebt, wohl aber einklammert: „In einer paradox anmutenden Mischung von Identifikation (mit der sprechenden Gottheit) und Distanz (durch den Zitatcharakter des Gesprochenen) gelingt mit dem Erzählen der

68 Vgl. ACHIM Masser: ,Gebete und Benediktionen aus Muri'. In: Die deutsche Literatur des Mittelalters. Verfasserlexikon. Zweite, völlig neu bearbeitete Aufl., Bd. 2, Berlin, New York 1980, Sp. 1110-1112; PETER OCHSENBEIN: Das Gebetbuch von Muri als frühes Zeugnis privater Frömmigkeit einer Frau um 1200. In: Gotes und der werlde hulde. Festschrift für Heinz Rupp zum 70. Geburtstag. Hrsg. von RüdigeR SCHNELL, Bern 1989, S. 175-199.

69 Vgl. Peter Browe: Die Eucharistie als Zaubermittel im Mittelalter. In: Archiv für Kulturgeschichte 20 (1930), S. 134-154; wieder in: DeRs.: Die Eucharistie im Mittelalter (Anm. 39), S. 219-231, hier 219 f. Zum Liebeszauber RICHARD KIECKHEFER: Erotic magic in medieval Europe. In: Sex in the Middle Ages. A Book of Essays. Hrsg. von JOYCE SALISBURY, New York 1991, S. 30-55.

70 München, clm 7021; vgl. ANTON SCHÖNBACH: Studien zur altdeutschen Predigt. In: Sitzungsberichte der Akademie der Wissenschaften. Phil.-hist. KI. 192/VII (1900), S. 144; CHRISTA HABIGER-TUCZAY: Magie und Magier im Mittelalter, München 1992, S. 246.

71 Vgl. UWE JUNKER: Das Buch der Heiligen Dreifaltigkeit in seiner zweiten, alchemistischen Fassung (Kadolzburg 1433), Köln 1986 (Kölner medizinhistorische Beiträge 40); zuletzt dazu Olga Solovieva: Corpus Libri als Corpus Christi. Zur prekären Transsubstantiation des alchemistischen Sprachstoffs im Buch der Heiligen Dreifaltigkeit. In: Poetiken der Materie. Stoffe und ihre Qualitäten in Literatur, Kunst und Philosophie. Hrsg. von ThOMAS STRÄSSLE/ CAROLINE TORRA-MATTENKLOTT, Freiburg i.Br. 2005 (Rombach Wissenschaften. Litterae 132), S. 145-164; JOACHIM TELLE: ,Ulmannus'. In: Die deutsche Literatur des Mittelalters. Verfasserlexikon. Zweite, völlig neu bearbeitete Aufl., Bd. 11, Berlin, New York 2004, Sp. 1573-1580. 
Zaubergeschichte sterblichen Menschen das Kunststück, wirkmächtige Götterrede auszusprechen, ohne sich anzumaßen, selbst eine Gottheit zu sein."72 Analog dazu ist der Sprechakt in der Messe hoc est corpus meum ein zugleich referentiell-uneigentlicher und liturgisch-ernsthafter zwischen Magie und Spiel und verweisen die eucharistischen Deiktika des Spiels auf eine Fülle, die sich erst im Imaginären des Glaubens eröffnet.

Im Falle des lateinischen Liebeszaubers partizipiert der Gestus der Beschwörung per signa Dei et per omnes virtutes Dei (Z. 50 f.) an der Macht des Gebets, die er umlenkt auf das Kraut und über dieses auf den begehrten Körper. Er gehorcht einer Mechanik des Heils, die, spätmittelalterlichen Frömmigkeitspraktiken nicht unähnlich, das faktisch nicht Berechenbare in ein Kalkül zwingen will. ${ }^{73} \mathrm{Im}$ Zentrum steht eine doppelte Analogie: zwischen dem Spruch und dem Gebet sowie zwischen dem Kraut und magisch wirksamen christlichen Objekten wie der Hostie oder den Reliquien. Wie jene ist Verbena, als herba pura geltend, ${ }^{74}$ eine Verkörperung des Übernatürlichen, an das sich der Mensch hilfesuchend wendet, eine Repräsentation der Macht, die alles vermag: ut modo audias me et facias me precepta (Z. 16 f.). Doch anders als jene ist Verbena keine realsymbolische Größe, die Heil und Heilsgeschichte in nuce enthält. Sie ist nur deren Transportmittel, ist als Pflanze ein Teil der Natur und ein Medium der Übertragung, das der Kräfte bedarf, die es speisen. Anders aber auch als Maria, mit der sie verglichen wird, ist sie kein von Gott erkorenes und zu Gott erhobenes Gefäß, das den Menschen auf die Ebene des Göttlichen transportiert. Sie dient keiner Heilsübermittlung, sondern einer Einflussnahme, die wiederum ohne den Rückgriff auf das göttliche Wort nicht auskommt.

Im Spiel der Analogien und Differenzen wird schlaglichtartig etwas von der Verheißung deutlich, die nicht nur der Zauberspruch, sondern auch das ihm vorangehende Fronleichnamsspiel nährt: die Verheißung, in der Verbindung von Ding und Wort könne die Transzendenz als solche in der Immanenz wirksam werden. Was das Spiel kontrollieren muss, indem es präsentische Strategien dogmatisch rückversichert, kann der Spruch ausphantasieren - nur, um seinerseits, in einer klerikalen Handschrift aufbewahrt, den Formen der Kontrolle schließlich wieder zu unterliegen. Als die Handschrift (vor 1445) nach Neustift kam, strich ein Leser den Zauberspruch durch und fügte vielleicht ein anderer zum Spiel von Mariae Himmelfahrt und zum Osterspiel, im Blick auf

72 MeinOlf SChUmaCher: Geschichtenerzählzauber. Die Merseburger Zaubersprüche und die Funktion der historiola im magischen Ritual. In: Erzählte Welt - Welt des Erzählens. Festschrift für Dietrich Weber. Hrsg. von RÖDIGER ZYMNER u. a., Köln 2000, S. 201-215, hier 213 (ebd. auch zur Eucharistie).

73 ARNold ANGENENDT u. a.: Gezählte Frömmigkeit. In: Frühmittelalterliche Studien 29 (1995), S. 1-71; RACHEL FULTON: Praying by Numbers (2005, online: http://home.uchicago.edu/ $\sim$ rfulton/numbers.htm).

74 Vgl. IsIDOR: Etymologiae. Hrsg. von Wallace M. Lindsay, Oxford 1911, XVII, 9, 55. 
mögliche Aufführungen, marginale Rollenkennzeichnungen und Szenenmarkierungen hinzu. ${ }^{75}$ Die Federproben auf dem freien Blatt am Ende (nach dem Zauberspruch) stammen wohl von Benutzern, die sich mit einzelnen Rollen oder Passagen beschäftigten bzw. diese auf andere Blätter übertrugen - sie betreffen überwiegend Szenen fröhlich-derben Charakters. ${ }^{76}$ Doch stellte auch eben jene Person, welche die Marginalien anbrachte, dem Fronleichnamsspiel die Bemerkung voran: Incipit ludus utilis pro deuocionem simplicium intimandus/ et peragendus die corporis Christi uel infra octavas de fide katholica/ Sumentur persone litterate et apte et sic de aliis (f. $50^{\mathrm{v}}$ ). Die Notiz bringt in aller Kürze wesentliche Aspekte des Spiels auf den Punkt. Sein Datum: am Fronleichnamstag oder in der folgenden Octav. Sein Thema: der christliche Glaube. Seine Funktion: Förderung der Andacht der einfachen Leute. Seine Organisation: unter Mitwirkung geeigneter, gebildeter, schriftkundiger Personen - was anscheinend auch für die anderen Spiele (sic de aliis) zu gelten hat. So wie auch das Osterspiel trotz seiner ausgedehnten Krämerszenen mit seinem Schluss wieder fest in der lateinischen Liturgie verankert ist, so erfordert auch das Fronleichnamsspiel Sinn für theologische, dogmatische und liturgische Zusammenhänge. Der Benutzer überführt mit seinem Incipit vor dem Incipit den lyber de corpore Christi von neuem in einen ludus, kennzeichnet aber schon durch den Begriff peragendus dessen Charakter als Vollzug eines Musters (volkssprachige Glossare glossieren peragere mit volbringen). $\mathrm{Zu}-$ gleich verweist er auf die Notwendigkeit, die Kontrolle über die Durchführung des Vollzugs im Auge zu behalten, man möchte ergänzen: die Kontrolle über jene Präsenzphantasmen und Performanzexzesse im Auge zu behalten, von deren auch klerikaler Verbreitung der lateinische Zauberspruch zeugt.

Daraus lässt sich auch lernen: Es bringt wenig, das Mittelalter global als Zeitalter der Präsenz einzustufen. ${ }^{77}$ Interessanter dürfte es sein, die Formen, Mechanismen und Strategien herauszuarbeiten, die der Produktion wie der Kontrolle, der Steigerung wie der Eindämmung präsentischer Verfahrensweisen dienten und sich ihrerseits im Lauf der Zeit immer wieder veränderten. Gerade am Umgang mit der Eucharistie, mit Reliquien und Bildern lässt sich dies gut verfolgen. Im späteren Mittelalter kommt es nicht einfach zu einem exzessiven Ausspielen von Präsenzformen, sondern auch zu immer neuen Anläufen, diese zu entmaterialisieren und zu spiritualisieren, an Dogma und Liturgie rückzubinden. ${ }^{78}$ Dieses je neue Ineinander von Symbolisierung und

75 MAX SILLER: Die Innsbrucker Spielhandschrift und das geistliche Volksschauspiel in Tirol. In: ZfdPh 101 (1982), S. 389-411.

76 Hier S. 404.

77 So Peter CZERWInSKI: Gegenwärtigkeit. Simultane Räume und zyklische Zeiten, Formen von Regeneration und Genealogie im Mittelalter. Exempel einer Geschichte der Wahrnehmung II, München 1993 ,

78 Am Beispiel der eucharistischen Dimension des Altars HEIKE SCHLIE: Von außen nach innen, am Scharnier von Präsenz und Absenz. Die Gregorsmesse und die Medialität des Klappreta- 
Desymbolisierung wurde zwar im reformatorischen Diskurs von verschiedenen Seiten her aufgelöst, spätestens im nach- und gegenreformatorischen aber neu in Geltung gesetzt, teilweise unter Verschiebung auf andere Schauplätze. ${ }^{79}$ Ähnliches wäre wohl für die memorialen Dimensionen zu beobachten: Sie stehen nicht nur im Zusammenhang der Heilsvergewisserung und Traditionssicherung, sondern auch der Argumentation und Abgrenzung. Sie oszillieren zwischen einem materiellen und einem spirituellen Übertragungsmodell, wobei das zweitere zwar im späteren Mittelalter an Dominanz gewinnt, ${ }^{80}$ das erstere aber noch bis in die frühneuzeitlichen Sehtheorien hinein eine Rolle spielt.

Schließlich die performativen Dimensionen: Sie beschränken sich nicht auf das, was in konkreten Aufführungen zum Austrag gekommen sein mag. Sie betreffen die grundsätzlichen Möglichkeiten schriftlicher Aufzeichnungen, den Status der Schrift als bloßes Medium der Registratur zu überschreiten: indem Sachverhalte prozessual entfaltet werden, indem Texte sich einschreiben in die Memoria einer Gemeinschaft, indem es zur Partizipation an liturgischen, kultischen und rituellen Vollzügen kommt. Auch dies wird mit der Umstellung auf mechanische Vervielfältigung nicht einfach beseitigt. Wohl aber bedingt die Ausdifferenzierung literarischer, künstlerischer und theatraler Praktiken jenes Unselbstverständlichwerden, das wiederum neue Auratisierungen ermöglicht. So verstanden, könnten Präsenz, Memoria und Performativität eine Matrix eröffnen, in der sich die Medialität (volkssprachiger) mittelalterlicher bzw. vormoderner Texte differenzierter als bisher beschreiben ließe. ${ }^{81}$

bels. In: Das „Goldene Wunder" in der Dortmunder Petrikirche. Bildgebrauch und Bildproduktion. Hrsg. von Barbara Welzel/Thomas LenteS/HeIKe Schlie, Bielefeld 2003 (Dortmunder Mittelalter-Forschungen 2), S. 201-222.

79 Vgl. JOACHIM KÜPPER: Repräsentation und Real-Präsenz. Bemerkungen zum auto sacramental (Calderón: Psiquis y Cupido). In: Theatralität und die Krisen der Repräsentation. Hrsg. von ERIKA FISCHER-LiCHTE, Stuttgart, Weimar 2001 (Germanistische Symposien. Berichtsbd. 22), S. 83-100. Zu den Möglichkeiten einer Bildpräsenz des Transzendenten Victor I. STOICHITA: Das mystische Auge. Vision und Malerei im Spanien des Goldenen Zeitalters, München 1997. LENTES, Auf der Suche (Anm. 15).

81 Das ist eines der Ziele des neuen vom Schweizerischen Nationalfonds und der Universität Zürich geförderten Nationalen Forschungsschwerpunkts Medienwandel - Medienwechsel Medienwissen. Historische Perspektiven, dessen Teilprojekt C.1. sich besonders mit dem geistlichen Spiel beschäftigt (vgl. www.mediality.ch). 